\title{
EL FUTURO DE LA PESCA EN EL OCÉANO ÁRTICO CENTRAL: ALCANCE Y CONTENIDO DEL ACUERDO PARA IMPEDIR LA PESCA NO REGLAMENTADA
}

\section{THE FUTURE OF FISHING IN THE CENTRAL ARCTIC OCEAN: SCOPE AND CONTENT OF THE AGREEMENT TO PREVENT UNREGULATED FISHING}

\author{
XAVIER Pons Rafols* \\ Catedrático de Derecho Internacional Público \\ Universidad de Barcelona \\ xpons@ub.edu
}

Fecha de recepción: 13 de septiembre de 2019 / Fecha de aceptación: 2 de diciembre de 2019

RESUMEN: El cambio climático, con la progresiva disminución del grosor y de la extensión de la capa de hielo, está acelerando los riegos medioambientales globales y regionales en el Océano Ártico. Entre los múltiples problemas a los que habrá que hacer frente, en este estudio se analiza la posible introducción de actividades de pesca comercial en las aguas de alta mar del Océano Ártico central y la regulación internacional de la pesca en alta mar y de la protección del medio marino ártico. Foco central de este estudio es el análisis del recientemente adoptado Acuerdo para impedir la pesca no reglamentada en alta mar en el Océano Ártico central, del que son signatarios los cinco Estados ribereños árticos y otros cinco sujetos de Derecho Internacional con flotas pesqueras de altura y con interés real en las pesquerías árticas.

\footnotetext{
* Este estudio se enmarca en el proyecto de investigación DER-2017-85406, financiado por el Ministerio de Economía y Competitividad y en las actividades de la Cátedra Jean Monnet de Derecho Ambiental de la Unión Europea de la Universidad de Barcelona.
} 
RESUM: El canvi climàtic, amb la progressiva disminució del grossor i de l'extensió de la capa de gel, està accelerant els riscos mediambientals globals i regionals en l'Oceà Àrtic. Entre els múltiples problemes als que s'haurà de fer front, en aquest estudi s'analitza la possible introducció d'activitats de pesca comercial en les aigües d'alta mar de l'Oceà Àrtic central i la regulació internacional de la pesca en alta mar i de la protecció del medi marí àrtic. Focus central d'aquest estudi és l'anàlisi del recentment adoptat Acord per impedir la pesca no reglamentada en alta mar en l'Oceà Àrtic central, del que són signataris els cinc Estats riberencs àrtics i altres cinc subjectes de Dret Internacional amb flotes pesqueres d'altura i amb interès real en les pesqueries àrtiques.

ABSTRACT: Climate change, with the progressive decrease in the thickness and extension of the ice sheet, is accelerating global and regional environmental risks in the Arctic Ocean. Among the many problems that will have to be tackled, this study analyses the possible introduction of commercial fishing activities in the waters of high seas of the central Arctic Ocean and the international regulation of high sea fisheries and the protection of the Arctic marine environment. Focus central of this study is the analysis of the recently adopted Agreement to Prevent Unregulated High Seas Fisheries in the Central Arctic Ocean, of which the five Arctic coastal States and five other subjects of International Law with high-seas fisheries fleets and with real interest in Arctic fisheries are signatories.

PALABRAS CLAVE: Derecho Internacional - Océano Ártico central - Alta mar - Pesca no reglamentada - Principio de precaución - Acuerdo regional de ordenación pesquera

PARAULES CLAU: Dret Internacional - Oceà Àrtic central - Alta mar - Pesca no reglamentada - Principi de precaució - Acord regional d'ordenació pesquera KEYWORDS: International Law - Central Arctic Ocean - Highs seas Unregulated fisheries - Precautionary principle - Regional fisheries management arrangement 
SUMARIO: I. Introducción. II. El Océano Ártico central como espacio marino de alta mar. III. La regulación internacional de la pesca en alta mar y el proceso hacia la adopción de un instrumento convencional específico para el Océano Ártico central. 1. La pesca en alta mar en el Derecho Internacional. 2. La protección del medio marino ártico y la adopción del Acuerdo POAC. IV. Análisis del Acuerdo para impedir la pesca no reglamentada en alta mar en el Océano Ártico central. 1. Los objetivos y el ámbito de aplicación del Acuerdo POAC. 2. El alcance de la limitación temporal de la pesca comercial en el Acuerdo POAC. 3. La investigación científica en el Acuerdo POAC. 4. La participación en el Acuerdo y las perspectivas futuras del Acuerdo POAC. V. Consideraciones finales. VI. Bibliografía.

\section{INTRODUCCIÓN}

El hilo conductor de la relativa actualidad que significa la firma en llulissat (Groenlandia), el 3 de octubre de 2018, del Acuerdo para impedir la pesca no reglamentada en alta mar en el Océano Ártico central (en adelante el Acuerdo o el Acuerdo POAC) ${ }^{1}$ constituye una ocasión idónea para analizar su alcance y contenido y formular un rápido panorama del futuro de las pesquerías en el Ártico. La cuestión, como a ningún lector avezado se le escapa, es que el cambio climático y el calentamiento global están provocando una progresiva reducción del grosor y de la extensión de la superficie helada en el Océano Ártico, lo que puede tener transcendentales consecuencias medioambientales de alcance regional y global $^{2}$. A los efectos que interesan en este estudio, esta situación puede provocar importantes cambios metabólicos en la biodiversidad marina de la zona, generar desconocidos movimientos migratorios de especies ictiológicas hacia aguas más frías y, especialmente, favorecer la introducción de actividades pesqueras industriales y comerciales en un área hasta ahora

\footnotetext{
${ }_{1}$ Agreement to Prevent Unregulated High Seas Fisheries in the Central Arctic Ocean (CAOF Agreement or CAOFA). El Acuerdo fue autenticado en chino, francés, inglés y ruso siendo todas las versiones igualmente auténticas. La primera publicación de una versión en español de este Acuerdo figura en Anexo de la Propuesta de Decisión del Consejo relativa a la firma, en nombre de la Unión Europea, del Acuerdo para impedir la pesca no reglamentada en alta mar en el Océano Ártico central, Documento COM(2018) 454 final, de 12 de junio de 2018.

2 De manera general, sobre estas cuestiones vid., en la doctrina española, las obras de A. MANERO SALVADOR, El Deshielo del Ártico: Retos para el Derecho Internacional. La delimitación de los espacios marinos y la protección y preservación del medio ambiente, Aranzadi/Thomson Reuters, Cizur Menor 2011; E. CONDE PÉREZ, "Geopolítica del Ártico: el Derecho Internacional ante los retos del cambio climático en la región", Cursos de Derecho Internacional y de Relaciones Internacionales de Vitoria-Gasteiz, UPH/UPV, 2015, pp. 99-160; y C. CINELLI, "La protección del medio ambiente ártico: desarrollos recientes", en M. SOBRIDO PRIETO (ed.), Espacios polares y cambio climático: desafíos jurídico-internacionales, ed. Tirant lo Blanch, Valencia 2017, pp. 167-184. Además del riesgo de una sobreexplotación pesquera en la zona, otros riesgos principales derivados del deshielo del Ártico son la contaminación por hidrocarburos y la navegación en las aguas árticas (A. MANERO SALVADOR, "La protección ambiental del Ártico y la Agenda 2030", Actualidad Jurídica Ambiental, núm. 77, 2018, p. 9).
} 
ajena a estas actividades. Estos riesgos son los que se quieren prevenir mediante la adopción y futura aplicación del Acuerdo objeto de este estudio.

A los efectos de abordar el análisis del futuro de las pesquerías en el Ártico y de este reciente Acuerdo internacional ordeno estas páginas en tres apartados. En primer lugar, abordo un planteamiento general sobre la condición de alta mar de las aguas del Océano Ártico central (I). En segundo lugar, analizaré la regulación internacional de la pesca en el espacio marino de alta mar y el enfoque de los Estados ribereños sobre el medio marino ártico y el futuro de las pesquerías en el Océano Ártico central, así como el proceso que ha conducido a la adopción del Acuerdo POAC (II). El tercer apartado de este estudio está dedicado precisamente al análisis pormenorizado del alcance y contenido del citado Acuerdo, del que también es parte firmante la Unión Europea (en adelante UE) ${ }^{3}$, lo que le da, desde nuestra perspectiva, aún, mayor interés (III).

\section{EL OCÉANO ÁRTICO CENTRAL COMO ESPACIO MARINO DE ALTA}

\section{MAR}

El histórico espacio marino de alta mar ha quedado claramente delimitado, desde la primera Conferencia de las Naciones Unidas sobre el Derecho del Mar celebrada en 1958, como aquel espacio marino que se halla al margen de la jurisdicción de los Estados ribereños ${ }^{4}$. En todo caso, lo que ha pasado en recientes décadas es que se han ampliado los espacios sobre los que los Estados ejercen su jurisdicción reduciendo así, más aún, el espacio de alta mar. Esto se llevó a cabo, principalmente, en la tercera Conferencia de las Naciones Unidas sobre el Derecho del Mar, que concluyó en 1982 con el actual

\footnotetext{
${ }^{3}$ El Acuerdo fue firmado por la Unión Europea el 3 de octubre de 2018 con la autorización del Consejo [Decisión (UE) 2018/1257, de 18 de septiembre de 2018, DO L 238, de 21 de septiembre de 2018). Después de la correspondiente aprobación del Parlamento Europeo [Resolución legislativa del Parlamento Europeo, de 12 de febrero de 2019, sobre el proyecto de Decisión del Consejo relativa a la celebración, en nombre de la Unión Europea, del Acuerdo para impedir la pesca no reglamentada en alta mar en el Océano Ártico central (P8_TAPROV(2019)0066)] el Consejo adoptó la Decisión (UE) 2019/407, de 4 de marzo de 2019, relativa a la celebración, en nombre de la Unión Europea, del Acuerdo para impedir la pesca no reglamentada en alta mar en el Océano Ártico central ( $D O L$ 73, de 15 de marzo de 2019).

${ }^{4}$ El artículo 1 de la Convención de Ginebra de 29 de abril de 1958 sobre Alta Mar entiende por alta mar "la parte del mar no perteneciente al mar territorial ni a las aguas interiores de un Estado" (BOE de 27 de diciembre de 1971, UNTS, vol. 450, p. 11).
} 
y fundamental texto internacional de referencia que constituye la Convención de las Naciones Unidas sobre el Derecho del Mar (en adelante CNUDM) 5 .

En esta Convención, al también histórico espacio marino del mar territorial -que se amplió hasta las 12 millas-, se añadió especialmente el nuevo espacio de la zona económica exclusiva que alcanza hasta las 200 millas a partir de las líneas de base y sobre la que los Estados ribereños ejercen competencias, en lo que ahora interesa y entre otras, en materia de exploración, explotación, conservación y ordenación de los recursos vivos, es decir, de los recursos pesqueros ${ }^{6}$. Es el Estado ribereño el que ejerce derechos de soberanía en este espacio, estableciendo las correspondientes medidas de conservación y ordenación sostenible y, en este sentido, determinando el total de capturas pesqueras permisibles. Si no tiene capacidad pesquera suficiente para explotar todas las capturas permisibles, el Estado ribereño, bajo su control y medidas, puede dar acceso al excedente a los buques pesqueros de otros Estados ${ }^{7}$. La tradicional libertad de pesca en alta mar se ve, así, progresivamente reducida en términos espaciales y, como veremos más adelante, también en términos materiales.

En relación con el espacio que nos ocupa, el Ártico, debe indicarse inicialmente que es un espacio de conceptualización diversa en función de los distintos posibles criterios aplicables. En los términos generalmente convenidos, podemos indicar que es todo aquel espacio, ya sea marino o terrestre, situado por encima del Círculo polar ártico, es decir, por encima del paralelo de latitud 66우 33' 52" Norte ${ }^{8}$. Con esta concepción, son ocho los Estados situados en el Ártico: Estados Unidos (por Alaska), Canadá, Dinamarca (por Groenlandia), Islandia, Noruega, Suecia, Finlandia y Rusia. Ahora bien, a nuestros efectos, sólo cinco de estos ocho Estados están bañados propiamente por aguas de la cuenca ártica, ya que ni Suecia ni Finlandia tienen costa en el Océano Ártico, e

\footnotetext{
${ }^{5}$ Convención adoptada el 10 de diciembre de 1982 en Montego Bay (Jamaica), en vigor desde el 16 de noviembre de 1994 y para España el 14 de febrero de 1997 (BOE de 14 de febrero de 1997, UNTS, vol. 1833, p. 3).

${ }^{6}$ Artículo 56.1 de la CNUDM.

7 Tal como establecen, en particular, los arts. 61 y 62 de la CNUDM.

8 Aproximadamente, ya que la latitud es fluctuante y depende de la inclinación del eje de rotación de la tierra con respecto a la eclíptica. Otro criterio, el de la temperatura, considera que son árticos aquellos espacios, terrestres o marítimos, en los que la temperatura media durante el mes de julio no supera la línea isotérmica de los $10^{\circ} \mathrm{C}$, lo que abarcaría espacios marinos de alta mar del Océano Atlántico septentrional y del Océano Pacífico septentrional.
} 
Islandia está situada fuera de esta área, justo al sur del Círculo polar ártico ${ }^{9}$. Bajo esta perspectiva, además, se acaban excluyendo de la cuenca ártica otras aguas de las zonas septentrionales tanto del Océano Pacífico como del Océano Atlántico.

Estos cinco Estados ribereños de las aguas de la cuenca ártica (Estados Unidos, Rusia, Noruega, Dinamarca y Canadá) han delimitado sus zonas económicas exclusivas, aunque es conocido que mantienen disputas y reclamaciones territoriales tanto respecto a estas mismas zonas como, especialmente, en relación con el alcance de sus respectivas plataformas continentales ${ }^{10}$. Haciendo abstracción de estas disputas y reclamaciones territoriales, podemos conceptualizar el espacio marino de aguas de alta mar en el Océano Ártico como aquellas aguas árticas que están más allá de las zonas económicas exclusivas de jurisdicción de los cinco Estados ribereños.

\footnotetext{
9 Aunque algunas islas islandesas están situadas dentro del Círculo polar ártico (fundamentalmente la pequeña isla de Grimsey).

${ }_{10}$ Además de las obras citadas en la Nota 2 puede verse también, de manera general, C. CINELLI, El Ártico ante el derecho del mar contemporáneo, Tirant lo Blanc, Valencia 2012; J. AlCAIDE FERnÁNDEZ, C. CINELLI, "La 'cuestión ártica' y el Derecho Internacional", Revista Española de Derecho Internacional, 2009.2, pp. 381-409; y E. CONDE PÉREZ, "Delimitaciones marítimas y territoriales en el Ártico: desarrollo y tendencias", Revista Española de Derecho Internacional, 2016.1, pp. 235-239.
} 


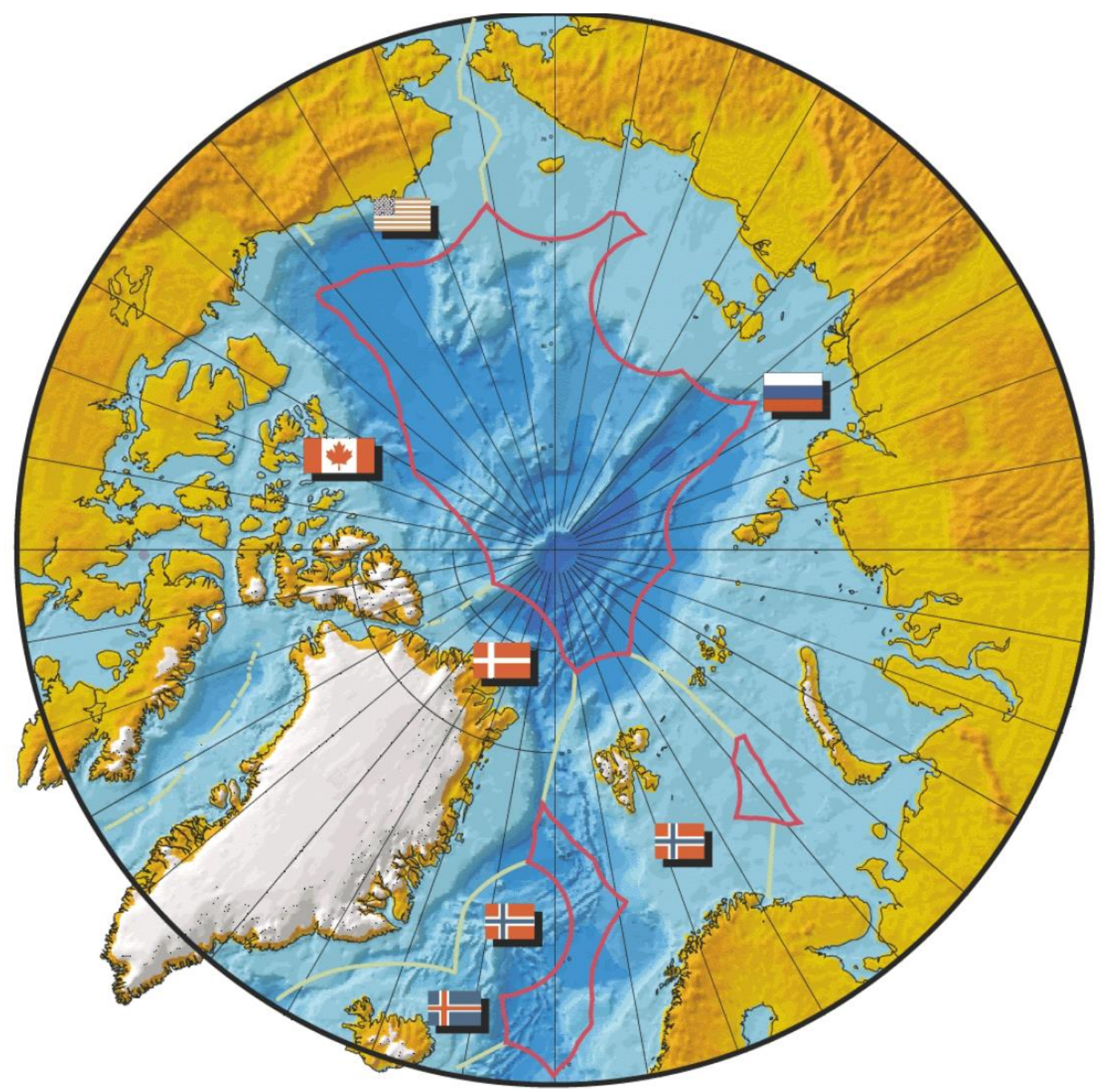

El Océano Ártico central y otros espacios marinos de alta mar, delimitados por líneas rojas (la latitud que encierra este mapa no se corresponde con la del Círculo polar ártico).

Fuente: https://www.ngdc.noaa.gov/mgg/bathymetry/arctic/copenfigs.html.

Estos espacios marinos de alta mar comprenden una amplia zona central, de más de 2,8 millones de quilómetros cuadrados ${ }^{11}$ que, hasta el momento, se encuentra en general cubierta de hielo todo el año. Al margen de este espacio central, otras zonas de aguas árticas de alta mar se encuentran situadas entre las zonas económicas exclusivas de los Estados en otras posiciones geográficas. Así, se hallan en esta situación dos zonas de alta mar más pequeñas: el denominado Banana Hole, en el Atlántico septentrional, entre las zonas económicas exclusivas que generan la Noruega continental y la isla

11 Algo superior a la total extensión del Mar Mediterráneo, zonas económicas exclusivas incluidas. 
noruega de Jan Maien y el Loophole, en el Mar de Barents, entre las zonas económicas exclusivas de Noruega (por las islas Svalbard) y Rusia. También es alta mar, pero se halla fuera de la cuenca ártica del Océano Ártico, el denominado Donut Hole, en el Mar de Bering, en el Océano Pacífico septentrional, entre las zonas económicas exclusivas de Rusia y de los Estados Unidos.

\section{LA REGULACIÓN INTERNACIONAL DE LA PESCA EN ALTA MAR Y EL PROCESO HACIA LA ADOPCIÓN DE UN INSTRUMENTO CONVENCIONAL ESPECÍFICO PARA EL OCÉANO ÁRTICO CENTRAL}

Establecido el carácter de alta mar del Océano Ártico central debe abordarse ahora, de un lado, la regulación internacional de la pesca en este espacio marino (1); y, de otro lado, la protección del medio marino ártico y el enfoque adoptado por los Estados ribereños árticos que les ha conducido a establecer una moratoria para la pesca y a incorporarla en un instrumento jurídico vinculante, como es el Acuerdo POAC (2).

\section{La pesca en alta mar en el Derecho Internacional}

A partir de lo indicado en el apartado anterior, debe seguirse que en la medida en que las aguas del Océano Ártico central son aguas de alta mar les son de aplicación las normas internacionales sobre la pesca en este espacio marino. Esta regulación internacional ha ido comportando, en las últimas décadas, el establecimiento de límites a la tradicional libertad de pesca en alta mar desde la perspectiva material de la conservación de los recursos; perspectiva que podemos reconducir al criterio del máximo rendimiento sostenible posible. Este era el enfoque ya incorporado en la Convención sobre pesca y conservación de los recursos vivos de la alta mar, adoptada en la ya citada Primera Conferencia de las Naciones Unidas sobre el Derecho del Mar de 1958. En ella se alertaba sobre los riesgos que el incremento de la capacidad pesquera podía tener por la explotación en exceso de los recursos pesqueros, se establecía el criterio del 
rendimiento óptimo constante, y se establecía la obligación de cooperación internacional para la conservación de los recursos vivos afectados ${ }^{12}$.

De esta manera, han ido surgiendo obligaciones internacionales de conservación y ordenación de los recursos pesqueros, así como obligaciones de cooperación internacional que pretenden casar -con ciertas dificultades- los intereses de los Estados ribereños con los intereses de los Estados de pesca a distancia o de altura. Esta evolución ha acabado por confluir en el concepto de pesca responsable -de enfoque más ecosistémico- planteado en este ámbito por la Organización de las Naciones Unidas para la Alimentación y la Agricultura (en adelante FAO) y que se explicitó en el Código de Conducta para la Pesca Responsable de $1995^{13}$. El Código enuncia principios y normas aplicables a la conservación, ordenación y desarrollo de todas las pesquerías de forma responsable, sirviendo como instrumento de referencia para los Estados y proporcionando orientaciones para la cooperación internacional mediante la adopción de acuerdos internacionales y otros instrumentos jurídicos, tanto obligatorios como voluntarios.

En cualquier caso, las principales normas convencionales aplicables a la pesca en alta mar son, además de la CNUDM y de la ya citada Convención de 1958 sobre pesca y conservación de los recursos vivos de la alta mar, el Acuerdo de las Naciones Unidas sobre la aplicación de las disposiciones de la Convención de las Naciones Unidas sobre el Derecho del Mar, de 10 de diciembre de 1982, relativas a la conservación y la ordenación de las poblaciones de peces transzonales y las poblaciones de peces altamente migratorios de 4 de agosto de 1995 (Acuerdo sobre poblaciones de peces de 1995) ${ }^{14}$, y el Acuerdo de la FAO para promover el cumplimiento de las medidas internacionales de conservación y ordenación por los buques pesqueros que pescan en alta mar de 24 de noviembre de 1993 (Acuerdo sobre cumplimiento de 1993) ${ }^{15}$. Se trata

12 Vid. el preámbulo y, en especial, los artículos 2 y 4 de la Convención sobre pesca y conservación de los recursos vivos de la alta mar, hecha en Ginebra el 29 de abril de 1958 (BOE de 27 de diciembre de 1971, UNTS, vol. 559, p. 285).

${ }^{13}$ El Código de Conducta para la Pesca Responsable fue adoptado por la Conferencia de la FAO el 31 de octubre de 1995, disponible en http://www.fao.org/3/a-v9878s.pdf. Esta y todas las otras referencias web que se citan a partir de ahora han sido consultadas y revisadas por última vez el 15 de noviembre de 2019.

${ }^{14}$ BOE de 21 de julio de 2004, UNTS, vol. 2167, p.3).

15 DO L 177, de 16 de julio de 1996. Ambos Acuerdos son de gran importancia, aunque el Acuerdo sobre cumplimiento de 1993 tenga un ámbito de aplicación espacial restringido 
de Acuerdos internacionales que tienen una participación diversa, incluso entre los mismos Estados árticos ya que, por ejemplo, ni Canadá ni Noruega ni Rusia son partes en la Convención de 1958, ni los Estados Unidos son parte de la misma CNUDM, o Rusia que tampoco es parte en el Acuerdo sobre cumplimiento de $1993^{16}$.

Todos estos Acuerdos, y principalmente el Acuerdo sobre poblaciones de peces de 1995, del que sí son partes todos los Estados ribereños árticos, al pretender asegurar el uso sostenible de las poblaciones de peces, consagran el criterio de precaución en la conservación, ordenación y exportación de los recursos pesqueros. Un criterio de precaución de alcance general ante las incertidumbres que la sobreexplotación pesquera y el deterioro del medio marino generan respecto de la preservación de estos recursos fundamentales, no solo para la alimentación humana sino también para el mantenimiento de la diversidad biológica del planeta. En este sentido, adicionalmente a las obligaciones que se establecen en relación con la conservación y ordenación de los recursos naturales en el espacio de la zona económica exclusiva que corresponden al Estado ribereño, puede afirmarse la obligación general para todos los Estados de cooperar y adoptar medidas para la conservación y administración de los recursos vivos de alta mar y, de manera especial, en relación con las poblaciones de peces transzonales y altamente migratorios ${ }^{17}$, aspecto que desarrolla específicamente el Acuerdo sobre poblaciones de peces de 1995.

Es decir, los Estados tienen obligaciones respecto de las actividades de los buques de su pabellón, pero también obligaciones de cooperación para el aprovechamiento óptimo de los recursos pesqueros tanto en las zonas sometidas a su jurisdicción -las respectivas zonas económicas exclusivascomo más allá de éstas zonas -el alta mar-. De ahí que se generen claras obligaciones internacionales, convencionales y de carácter consuetudinario. De un lado, como digo, para los Estados de pabellón, aunque la exigencia internacional del cumplimiento de estas obligaciones sigue teniendo un carácter

exclusivamente al alta mar y el Acuerdo sobre poblaciones de peces de 1995 tenga un ámbito de aplicación material restringido a las especies transzonales y altamente migratorias.

${ }^{16}$ Del que, por otro lado, es parte la Unión Europea y no sus Estados Miembros.

${ }^{17}$ Artículos 117,118 y 119 de la CNUDM. 
excesivamente limitado ${ }^{18}$. De otro lado, la CNUDM y los otros Acuerdos establecen, asimismo, una obligación general de cooperación -que también es de carácter consuetudinario- entre Estados cuyos nacionales explotan los mismos o diferentes recursos en la misma zona del alta mar y los Estados ribereños ${ }^{19}$. Esta cooperación internacional puede llevarse a cabo a través de acuerdos regionales de ordenación pesquera o de organizaciones regionales de ordenación pesquera (en adelante AROPs y OROPs respectivamente). El Acuerdo sobre poblaciones de peces de 1995 desarrolla esta cooperación institucionalizada determinando que pueden participar en AROPs y OROPs los Estados con "interés real" en una pesquería y estableciendo las correspondientes obligaciones de cumplimiento ${ }^{20}$.

El objetivo de estos AROPs y OROPs -algunos de los cuales se han establecido en el marco de la FAO- es la adopción, vigilancia y control de las medidas de conservación y ordenación de los recursos marinos vivos en determinadas zonas marinas que se encuentran fuera de la jurisdicción de los Estados. En las últimas décadas, se han establecido diversos AROPs y OROPs, tanto para determinados espacios geográficos marinos y para todas las especies ictiológicas de estos espacios que fueran susceptibles de captura pesquera, como para determinadas especies concretas en todos los espacios 0 sólo en determinados espacios marinos ${ }^{21}$. Algunos AROPs y OROPs existentes pueden resultar relevantes, como veremos, en relación con las pesquerías en el Océano Ártico central, aunque no existía hasta ahora ninguno de carácter específico.

Adicionalmente, desde la FAO se ha promovido desde hace unos años la lucha contra la pesca ilegal, no declarada y no reglamentada (pesca INDNR en adelante) $)^{22}$. La evolución reciente de esta acción internacional, ante las profundas consecuencias ambientales -de manera especial en la biodiversidad

\footnotetext{
18 A la espera de un difícil acuerdo vinculante sobre las obligaciones de los Estados de pabellón en materia de conservación y ordenación de los recursos pesqueros, pueden verse las "Directrices Voluntarias para la actuación del Estado del pabellón", adoptadas por el Comité de Pesca de la FAO en junio de 2014, Documento COFI/2014/4.2/Rev.1.

${ }^{19}$ Artículo 118 de la CNUDM.

${ }^{20}$ Artículo 8 del Acuerdo sobre poblaciones de peces de 1995.

21 Vid., en general, E. VÁZQUEZ GóMEZ, Las Organizaciones internacionales de ordenación pesquera, Junta de Andalucía, Sevilla 2002.

${ }_{22}$ Conocida por sus siglas en inglés IUU Fishing (Illegal, Undeclared and Unreported Fishing).
} 
marina-, sociales y económicas que comporta la pesca INDNR, se ha generalizado a partir de la adopción por la FAO en 2001 del Plan de Acción Internacional para prevenir, desalentar y eliminar la pesca INDNR (PAIINDNR $)^{23}$ y, más recientemente, con la entrada en vigor del Acuerdo sobre las medidas del Estado rector del puerto destinadas a prevenir, desalentar y eliminar la pesca ilegal, no declarada y no reglamentada, adoptado por la Conferencia de la FAO el 22 de noviembre de 2009 (Acuerdo sobre las MEP) 24. En estos textos se conceptualizan estas tres nociones de pesca ilegal, de pesca no declarada y de pesca no reglamentada de una manera que ha sido aceptada internacionalmente ${ }^{25}$ y que abordaré más adelante en especial respecto de la denominada "pesca no reglamentada" a la que se refiere el Acuerdo POAC.

Por último, debo subrayar que, sin ningún género de dudas, la celebración de un futuro nuevo acuerdo internacional sobre la conservación y uso sostenible de la diversidad biológica marina en las zonas situadas fuera de la jurisdicción nacional -que, al cerrar este estudio, está en proceso de negociación en el marco de las Naciones Unidas ${ }^{26}$ - incidirá también en las condiciones

${ }^{23}$ EI PAI-INDNR fue aprobado por el Consejo de la FAO el 23 de junio de 2001 (vid. Informe del Consejo de la FAO, 120ำ período de sesiones, 18-23 de junio de 2001, Documento CL 120/REP, párrafo 9, disponible asimismo en http://www.fao.org/DOCREP/003/y1224s/y1224s00.HTM). Sobre el PAI-INDNR vid. A. REY ANEIROS, J. SOBRINO HEREDIA, "Plan de acción internacional para prevenir, desalentar y eliminar la pesca ilegal, no declarada y no reglamentada (Organización de las Naciones Unidas para la Agricultura y la Alimentación, Roma, 2001)", Revista Española de Derecho Internacional, 2002.1, pp. 481-487; W. EDESON, "The International Plan of Action on Illegal, Unreported and Unregulated Fishing: The Legal Context of a Non-Legally Binding Instrument", International Journal of Marine and coastal Law, 2001.6, pp. 603-623; y T. TREVES, "La pesca ilegal, no declarada y no reglamentada: Estado del pabellón, Estado costero y Estado del Puerto", en J. PUEYO LOSA; J. JORGE URBINA (coords.), La cooperación internacional en la ordenación de los mares y océanos, ed. lustel, Madrid 2009, pp. 135-158.

24 El Acuerdo entró en vigor el 5 de junio de 2016 y actualmente 61 Estados y una Organización Miembro (la Unión Europea) son partes en el mismo.

25 Puede indicarse, adicionalmente, la importante acción al respecto de la Unión Europea en este ámbito, adoptando reglamentaciones específicas y de gran impacto, aceptando las definiciones pertinentes de la FAO y ejerciendo un verdadero liderazgo en la lucha internacional contra la pesca INDNR [vid. al respecto X. PONS RAFOLS, "El protagonismo de la Unión Europea en la lucha contra la pesca ilegal, no declarada y no reglamentada", en J. PUEYO LOSA, J. JORGE URBINA (coord.), La gobernanza marítima europea: retos planteados por la reforma de la Política Pesquera Común, Thomson Reuters Aranzadi, Pamplona 2016, pp. 177-202].

26 Proceso puesto en marcha en 2015 y que en 2017 (vid. la Resolución 72/249, de la Asamblea General, de 24 de diciembre de 2017) llevó a la convocatoria de una conferencia intergubernamental para examinar las recomendaciones del Comité Preparatorio sobre los elementos del texto de un instrumento internacional jurídicamente vinculante en el marco de la Convención de las Naciones Unidas sobre el Derecho del Mar relativo a la conservación y el 
relacionadas con el Océano Ártico central y las actividades pesqueras en alta mar.

\section{La protección del medio marino ártico y la adopción del Acuerdo POAC}

En relación con la protección del medio marino ártico y su específico régimen jurídico debe señalarse, en primer lugar, que el artículo 234 de la CNUDM establece la que se denomina como "cláusula ártica" y que permite a los Estados adoptar normas para la protección ambiental contra la contaminación y que, de manera general, constituye una base jurídica fundamental para la adopción de medidas unilaterales de protección del medio marino ártico. Este objetivo de proteger y preservar el medio marino ártico lo ha implementado el Consejo Ártico ${ }^{27}$, que reúne a todos los Estados ribereños árticos, mediante mecanismos de soft law, ante la ausencia de un instrumento convencional específico sobre la protección del medio ambiente en la región ${ }^{28}$. En este sentido, debe indicarse que existen diversos foros e instrumentos relacionados con la protección del medio ambiente ártico y, en particular en relación con las pesquerías, pero sólo vamos a referirnos brevemente a los que afectan al Océano Ártico central ${ }^{29}$.

uso sostenible de la diversidad biológica marina de las zonas situadas fuera de la jurisdicción nacional [vid., al respecto, E. VÁZQUEZ GómEZ, "La protección de la diversidad biológica marina más allá de la jurisdicción nacional. Hacia un nuevo acuerdo de aplicación de la Convención de Naciones Unidas sobre el Derecho del mar", Revista Electrónica de Estudios Internacionales, núm. 37 (2019)].

27 Sobre el Consejo Ártico y la gobernanza en el Ártico vid., asimismo, J.R. FALLADA GARCíAVALLE, "La gobernanza en el Ártico: entre el realismo, la utopía y la distopía", Revista Catalana de Dret Ambiental, Vol. IX, Núm. 1 (2018), pp. 1-40.

28 A partir de la Estrategia de Protección Medioambiental del Ártico (Arctic Environmental Protection Strategy, AEPS en sus siglas en inglés) adoptada en Rovaniemi (Finlandia) en 1991 y las diversas actuaciones y grupos de trabajo en el seno del Consejo Ártico [vid. al respecto, en particular, P. PAREJA ALCARAZ, "El Ártico, como espacio de cooperación: evolución, contenido y límites", en J.M. SOBRINO HEREDIA (coord.), Mares y Océanos en un mundo en cambio. Tendencias jurídicas, actores y factores, ed. Tirant lo Blanch, Valencia 2007, en especial pp. 890 y ss.; y A. MANERO SALVADOR, "El Deshielo del Ártico ..", op. cit., pp. 161 y ss.]. ${ }^{29}$ Además de las obras citadas en la Nota 2 y en la nota anterior, cabe subrayar los enfoques panorámicos de L. WEIDEMANN, International Governance of the Arctic Marine Environment. With particular Emphasis on High Seas Fisheries, Springer, Hamburg Studies on Maritime Affairs, Vol. 27, 2014; R. BARNES, "International Regulation of Fisheries Management in Arctic Waters", German Yearbook of International Law, 54 (2011), pp. 193-230; E. J. MolenAAR, "Arctic Fisheries and International Law: Gaps and Options to Address Them", Carbon and Climate law Review, 2012.1, pp. 63-77; E. J. MolenAAR, "Arctic Fisheries Management", en E.J. MOLENAAR et al (eds.), The Law of the Sea and the Polar Regions: Interactions between Global and Regional Regimes, Martinus Nijhoff Publishers, Leyden 2013, pp. 243-266; E. J. MOLENAAR, "Status and Reform of International Arctic Fisheries Law", en E. TEDSEN et al. (eds.), 
El mismo Consejo Ártico y, concretamente, su Grupo de Trabajo sobre protección del medio ambiente marino del Ártico ${ }^{30}$, identificó a partir de 2006 hasta dieciocho grandes áreas marinas de especial protección (Arctic Large Marine Ecosystems, Arctic LME's) en las aguas del Océano Ártico y mares adyacentes. Estas áreas marinas de especial protección fueron posteriormente adoptadas por el Consejo Ártico y sirven de marco para prácticas de gestión basadas en un enfoque ecosistémico en el Ártico. Uno de estos grandes ecosistemas marinos árticos se corresponde prácticamente con el espacio del Océano Ártico central, aunque incorpora también aguas bajo la jurisdicción estatal ${ }^{31}$.

De otro lado, en el marco del Convenio sobre la protección del medio marino del Atlántico Nordeste (OSPAR Convention) se ha planteado la identificación de áreas marinas protegidas (en adelante AMPs), en el marco de su competencia de protección del medio marino ${ }^{32}$. De la Comisión OSPAR son partes, junto a otros Estados europeos, los Estados árticos europeos (Noruega, Dinamarca, Suecia e Islandia), pero ni Rusia, ni Canadá, ni los Estados Unidos, lo que convierte en dificultoso un abordaje completo de los problemas medioambientales árticos en su $\operatorname{seno}^{33}$. En todo caso, aunque no tiene competencias en materia pesquera, la actividad de la Comisión OSPAR, en colaboración con la Comisión de Pesquerías del Atlántico Nordeste (CPANE) -a la que enseguida me referiré- ha permitido que en el marco de la Convención sobre la Diversidad Biológica (en adelante CDB) se hayan designado en el Ártico hasta 11 AMPs o Ecologically or Biologically Significant Marine Areas (en

Arctic Marine Governance, Springer-Verlag Berlin Heidelberg 2014, pp. 103-125; y M. SoBRIDO PRIETO, "La gestión de los recursos pesqueros árticos en alta mar", en J.M. SobRINO HEREDIA, La toma de decisiones en el ámbito marino: su repercusión en la cooperación internacional y en la situación de las gentes del mar, ed. Bomarzo, Albacete 2016, pp. 279-304.

30 Protection of Arctic Marine Environment (PAME). Vid. mayor información en https://www.pame.is/.

${ }^{31}$ Así, esta LME alcanza una extensión de unos 3,8 millones de quilómetros cuadrados.

32 Vid. el texto del Convenio, hecho en París el 22 de septiembre de 1992, en el BOE de 24 de junio de 1998. La denominación Convenio OSPAR (y Comisión OSPAR) responde al hecho de que complementa y actualiza la Convención de Oslo de 1972 sobre vertidos al mar y la Convención de París de 1974 sobre contaminación marina de origen terrestre.

33 Como indica M. SOBRIDO PRIETO, "La gestión de los recursos pesqueros árticos ..", op. cit., en especial pp. 295-297. 
adelante EBSAs), dos de ellas en el Océano Ártico central ${ }^{34}$. Los criterios para la determinación de las EBSAs fueron adoptados en 2008 en la Conferencia de las Partes de la $\mathrm{CDB}^{35}$.

En relación específicamente con los recursos pesqueros debe indicarse también que, en 1980, heredando mecanismos anteriores, se estableció la Comisión de Pesquerías del Atlántico Nordeste (en adelante CPANE, NEAFC por sus siglas en inglés ${ }^{36}$ ), que es una OROP que mantiene controles sobre la pesca y los actos relacionados con la pesca en las aguas de alta mar del Océano Atlántico nororiental. En esta OROP solo participan la UE, Dinamarca (por Groenlandia), Islandia, Rusia y Noruega y no participan ni los Estados Unidos ni Canadá. En tanto que OROP, la CPANE tiene como objetivos el garantizar la conservación a largo plazo y la utilización óptima de los recursos pesqueros, proporcionando beneficios económicos, ambientales y sociales sostenibles. El área cubierta por el Convenio CPANE son todas las zonas de alta mar del Océano Atlántico nororiental que se extienden desde el extremo sur de Groenlandia, al este hasta el Mar de Barents, y al sur hasta Portugal. A los efectos que interesan en este momento, debe subrayarse que la CPANE cubre un 8 por ciento del área total del Océano Ártico central, en una especie de poliedro triangular irregular formado con vértice en el polo norte y las longitudes $42^{\circ}$ oeste y $51^{\circ}$ este, además de cubrir en su área de competencia tanto el Banana Hole como el Loophole ${ }^{37}$.

\footnotetext{
${ }^{34}$ Las áreas en cuestión son las denominadas The Marginal Ice Zone and the Seasonal IceCover Over the Deep Arctic Ocean y Multi-year Ice of the Central Arctic Ocean (vid. al respecto la información disponible en https://www.cbd.int/ebsa/ebsas).

35 Vid. los Criterios científicos para identificar áreas marinas de importancia ecológica o biológica que requieren protección, en aguas oceánicas abiertas y en hábitats de aguas profundas, en el Anexo 1 de la Decisión IX/20 de la COP 9 del CDB, celebrada del 19 al 30 de mayo de 2008.

36 North-East Atlantic Fisheries Commission. Convenio de 18 de noviembre de 1980 sobre la cooperación multilateral en los caladeros del Atlántico Nororiental, constitutivo de la Comisión de Caladeros del Atlántico Nororiental, vid. mayor información en https://www.neafc.org.

37 Ambos espacios de alta mar están también cubiertos por otras dos OROPs orientadas a especies concretas, una altamente migratoria (el atún) y otra anádroma (el salmón): la Comisión Internacional para la Conservación del Atún Atlántico (ICCAT en sus siglas en inglés, International Commission for the Conservation of Atlantic Tunas) y la Organización para la Conservación del Salmón del Atlántico Norte (NASCO en sus siglas en inglés, North Atlantic Salmon Conservation Organization). Por otro lado, otros foros tienen competencias en aguas del Océano Ártico como, por ejemplo, la Joint Norwegian-Russian Fisheries Commission.
} 


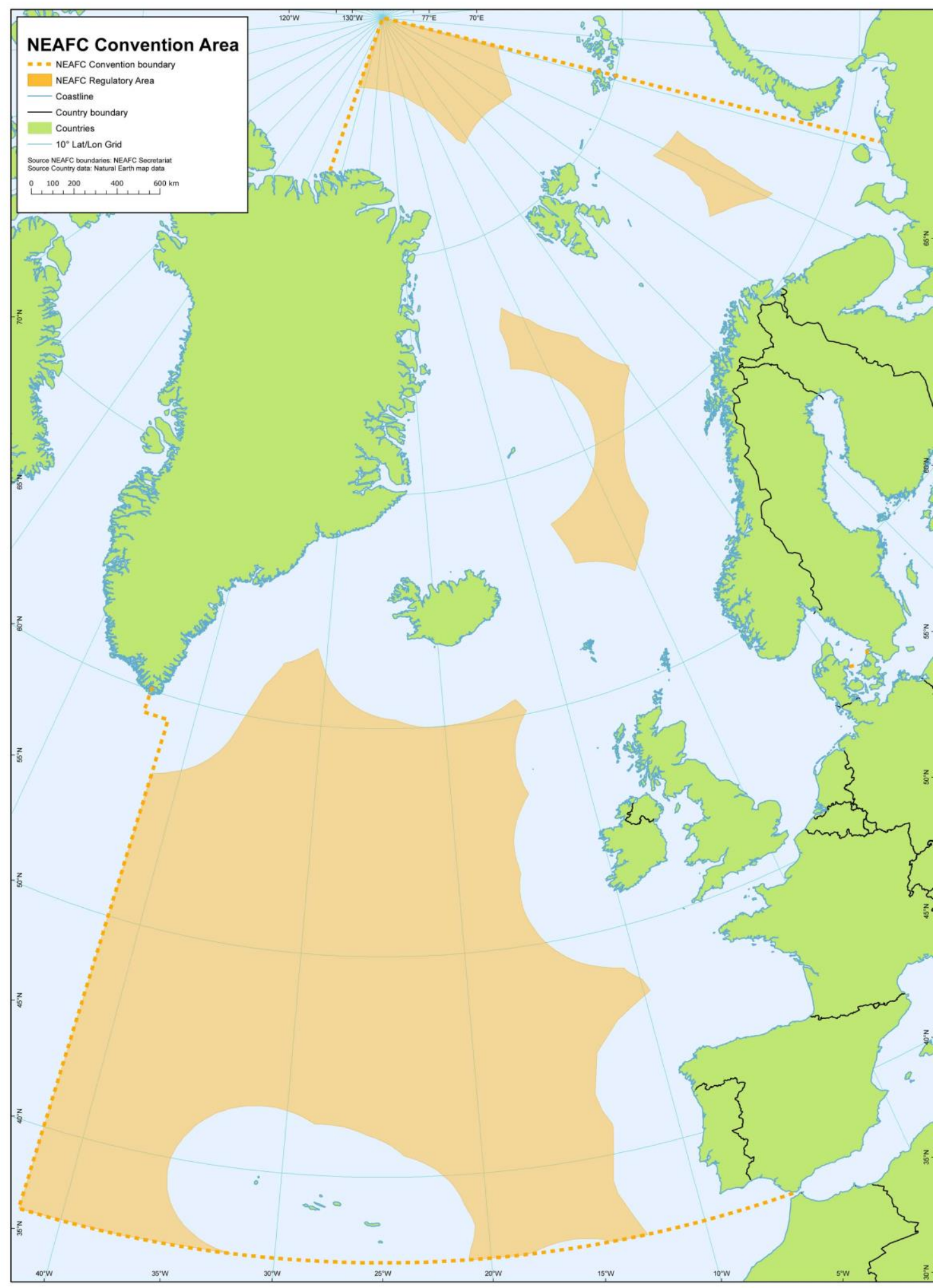

Área de competencia de la Convención y área de regulación de la CPANE/NEAFC Fuente: http://firms.fao.org/firms/fishery/479/en.

Más allá de estas acciones generales de protección del medio ambiente ártico, incluida la protección de los recursos marinos vivos, debe acentuarse 
especialmente el agravamiento de los problemas que el acelerado deshielo ártico puede generar en el ámbito de los recursos pesqueros. El hecho de que la zona de alta mar del Océano Ártico central estuviera recubierta de hielo todo el año impedía faenar en estas aguas, pero la disminución de la extensión y grosor de la capa de hielo puede hacerlo posible, con lo que los ecosistemas del Océano Ártico pueden estar expuestos a actividades humanas peligrosas para su mantenimiento y sostenibilidad. De esta manera, se empezó a generar una presión -antes inexistente- sobre la gestión de la gobernanza ártica en materia pesquera.

En efecto, las aguas árticas y subárticas están habitadas por más de 150 especies ictiológicas y 12 especies de mamíferos marinos, aunque existe todavía una muy limitada información científica sobre la gestión de los recursos marinos vivos en estas aguas. El deshielo ártico puede provocar, de un lado, importantes e ignotos cambios en las poblaciones de peces, en particular, en sus procesos metabólicos, fisiológicos y reproductivos por el cambio de temperatura del agua, por su salinidad o por su oxigenación. De otro lado, también pueden producirse alteraciones en las especies ictiológicas por los cambios en su medio ambiente biológico, ya sea por la expansión o contracción de las poblaciones de peces, las migraciones de peces, los movimientos transzonales de peces entre las aguas septentrionales del Océano Atlántico y del Océano Pacífico con intercambios bióticos repentinos o, por señalar un último aspecto, por la aparición de nuevos depredadores de determinadas especies $^{38}$.

\footnotetext{
38 En este sentido, un reciente Informe del Parlamento Europeo analizaba el número y volumen de las especies de peces en las aguas árticas y subrayaba que el deshielo ártico planteaba la posible ampliación de las áreas de pesca, al tiempo que se podía expandir el área ocupada por estas especies en la medida en que las temperaturas resultasen adecuadas para las mismas, pudieran encontrar alimento y las áreas de desove no se hallasen demasiado lejanas (vid. Fisheries Management and the Arctic in the Context of Climate Change, European Parliament, Directorate-general for Internal Policies, Policy Department, Structural and Cohesion Policies, 2015, disponible

en http://www.europarl.europa.eu/RegData/etudes/STUD/2015/563380/IPOL_STU(2015)563380_ EN.pdf). Algunas especies no encontrarán estas condiciones, pero otras especies pelágicas, como el bacalao polar, si pueden desarrollarse y prosperar y ser objeto, por tanto, de actividad pesquera en la zona de aguas árticas de alta mar. Además del bacalao, las principales especies afectadas son el abadejo, el corvinón, el capelán y el arenque [vid., en este sentido, el Informe (Factsheet) sobre la Central Arctic Ocean LME, elaborada por el PAME, disponible en https://www.pame.is/index.php/document-library/ecosystem-approach-to-managementdocuments/large-marine-ecosystems/398-13-central-arctic-ocean-Ime/file].
} 
Con todo ello, los Estados ribereños árticos (a nuestros efectos, los "Arctic Five" o A5) empezaron a considerar que más allá de las disposiciones de la CNUDM y del Acuerdo sobre poblaciones de peces de 1995 debía buscarse un marco jurídico complementario o más desarrollado ${ }^{39}$. Esta búsqueda confluía con planteamientos cada vez más extendidos internacionalmente en relación con lo que se ha venido en denominar jurisdicción progresiva o rampante (o creeping jurisdiction), mediante la que los Estados ribereños interesados pretenden, de facto, controlar las actividades en espacios fuera de su jurisdicción nacional -como el alta mar-, limitando así las actuaciones de otros Estados $^{40}$. De ahí que el enfoque se centrase en el Océano Ártico central, con lo que pudiera acabar ocurriendo que este espacio estuviera sujeto a una regulación más estricta que la aplicable por los Estados árticos en sus zonas económicas exclusivas ${ }^{41}$.

La ausencia específica de un AROP o una OROP, es decir, de una reglamentación internacional de carácter regional respecto al régimen de conservación, ordenación y gestión de los recursos pesqueros en el Océano Ártico central ${ }^{42}$, condujo a los cinco Estados árticos a poner en marcha un proceso para prevenir la pesca no reglamentada ante el acelerado cambio de las condiciones climáticas. Nos hallábamos, por tanto, ante una clara aplicación del criterio de precaución en la gestión de la pesca, de una manera que podríamos calificar como anticipatoria o de carácter preventivo, atendiendo a la mínima o nula incidencia hasta entonces de las actividades pesqueras de

\footnotetext{
39 La exclusividad pretendida de los cinco Estados ribereños árticos generó, obviamente, la protesta de los otros tres Estados árticos (Islandia, Suecia y Finlandia). De ahí que, finalmente, fueran invitados a incorporarse al proceso (aunque Suecia y Finlandia lo serían a través de la Unión Europea).

40 En respuesta a la insatisfacción de los Estados con amplias fachadas marítimas con las medidas internacionales de conservación y ordenación y que se corresponde con la doctrina chilena del "mar presencial", como zona de influencia del Estado ribereño en el alta mar adyacente a su zona económica exclusiva.

41 Vid., en este sentido, E. J. MolenAAR, "The Oslo Declaration on High Seas Fishing in the Central Arctic Ocean", Arctic Yearbook, 2015, p. 4.

42 Vid. L. WEIDEMANN, International Governance of the Arctic ..., op. cit., p. 139 y, en especial, pp. 161-195. Entre las debilidades, E. J. MolenAAR indica la ausencia de datos científicos, las inadecuadas regulaciones internas, las limitaciones de los instrumentos bilaterales existentes y la ausencia de cobertura del alta mar por AROPs u OROPs (E. J. MOLENAAR, "Arctic Fisheries and International Law: Gaps and Options ...", op. cit., pp.72 y ss.). Aunque algunos autores planteaban que la opción más fácil sería ampliar el ámbito de competencia regulatoria de la CPANE, no debe olvidarse su composición y, por tanto, la difícil legitimación de un proceso como este respecto de los Estados ribereños árticos no participantes en la CPANE (Vid. R. BARNES, "International Regulation of Fisheries Management ..., op. cit., p. 228).
} 
carácter comercial en la región. En un primer momento, en 2008, los representantes ministeriales de los A5 consideraron, mediante la Declaración de Ilulissat, que no era necesario ningún marco jurídico internacional especial para la cuenca ártica, ya que estimaban que el marco existente permitía ya una gestión ártica responsable ${ }^{43}$. Reiteraban, eso sí, su especial compromiso y responsabilidad en seguir asegurando la protección y preservación del frágil medio ambiente marino en el Océano Ártico y su voluntad de continuar con su estrecha cooperación.

A partir de ahí, las propias políticas nacionales de los Estados árticos, particularmente de los Estados Unidos ${ }^{44}$-así como la celebración de diversas reuniones científicas y de funcionarios de alto nivel entre los Estados ribereños árticos ${ }^{45}$-, fueron girando las posiciones hacia la necesidad de la adopción de nuevos instrumentos jurídicos, ya fueran éstos vinculantes o no vinculantes ${ }^{46}$. De esta manera, pocos años después, en julio de 2015, en una nueva reunión ministerial se adoptó la Declaración de Oslo mediante la que los A5 adoptaron una posición común respecto de la prevención de la pesca no regulada en alta mar en el Océano Ártico central ${ }^{47}$.

43 Vid. la Declaración de llulissat, de 28 mayo de 2008, reproducida en https://byers.typepad.com/arctic/ilulissat-declaration-may-28-2008.html.

44 En la US Senate Joint Resolution No. 17 of October 2007, House of Representatives May 2008, President Busch Signature 4 June 2008. Public Law 110-243, se establecía que "the United States should initiate international discussions and take necessary steps with other Arctic nations to negotiate an agreement or agreements for managing migratory, transboundary, and straddling fish stocks in the Arctic Ocean and establishing a new international fisheries management organization or organizations for the region" (disponible en https://www.congress.gov/110/plaws/publ243/PLAW-110publ243.pdf). Sobre la posición de los Estados Unidos vid., asimismo, K. DAUGIRDAS, J.D. MORTENSON, "United States reaches agreement to limit arctic fishing", American Journal of International Law, Vol. 112, 2018.2, pp. 313-315

${ }^{45}$ La más relevante de las cuales fue la reunión de Nuuk (Groenlandia) celebrada del 24 al 26 de febrero de 2014 y que alumbró el correspondiente Chairman's Statement que avanzaría las principales líneas de lo que después sería la Declaración de Oslo (vid. el Chairman's Statement disponible

en https://www.afsc.noaa.gov/Arctic_fish_stocks_third_meeting/Arctic\%20Fisheries\%20Nuuk\%20C hairmans\%20and\%20ToR\%20for\%203rd\%20Meeting.pdf).

${ }^{46}$ Aunque ante el impulso pro-activo de los Estados Unidos y el seguimiento de Canadá y Dinamarca, deben subrayarse las reticencias de Noruega y de Rusia que, además, ateniendo al grosor y a la extensión de la capa de hielo, son los Estados árticos con mayor accesibilidad al Océano Ártico central [vid., en este sentido, N. WEGGE, "The emerging politics of the Arctic Ocean. Future management of the living marine resources", Marine Policy, 51 (2015), p. 336].

47 Vid. la Declaración de Oslo de 16 de julio de 2015 reproducida en https://www.regjeringen.no/globalassets/departementene/ud/vedlegg/folkerett/declaration-onarctic-fisheries-16-july-2015.pdf. 
Los ejes centrales de esta fundamental Declaración de Oslo giraban en torno a la voluntad -en aplicación del criterio de precaución- de establecer, como medida de carácter provisional, una moratoria de la pesca comercial para los nacionales de los cinco Estados ribereños árticos en las zonas de alta mar del Océano Ártico central, hasta que se dispusiera de mayor información científica. En realidad, más que una moratoria, lo que se estableció en la Declaración fue la previsión de la posible autorización de pesca comercial a buques bajo la jurisdicción de los A5 "sólo en caso" de que ya hubiera medidas o estándares internacionales reconocidos y autorizados por un AROP o una OROP, ya estuviera éste o ésta establecida o fuera de futura creación. Con ello, obviamente, de un lado, se limitaba la pesca comercial no reglamentada y, de otro lado, se validaban también las medidas de la CPANE en su ámbito de aplicación parcial en el Océano Ártico central, organización a la que se remite expresamente la Declaración ${ }^{48}$. En la Declaración de Oslo se acordó, asimismo, promover la investigación científica en cooperación con otros mecanismos institucionales internacionales ${ }^{49}$.

En otras palabras, en la Declaración de Oslo se consagró claramente el criterio de precaución en relación con la posibilidad de la futura pesca comercial en el Océano Ártico central, pero también se reconocía su escasa probabilidad en ese momento, por lo que tampoco se consideraba necesario el establecimiento de una específica OROP para la región o subregión. Aunque no se planteaba establecer una OROP, sí que se recogía la necesidad de iniciar un proceso hacia la adopción de medidas internacionales de conservación y ordenación de la pesca en el Océano Ártico central ${ }^{50}$. De alguna manera, puede decirse que se venía a plantear un proceso por etapas: una moratoria provisional en un

\footnotetext{
48 Compatibilidad que implicaba el sobreentendido de que los Estados ribereños árticos miembros también de la CPANE (Dinamarca y Noruega) podían autorizar a sus buques pesqueros a llevar a cabo pesca comercial, aunque solo en el área de regulación de la CPANE en el Océano Ártico central, de conformidad con las medidas de conservación y gestión establecidas por esta OROP.

49 Vid. sobre la Declaración de Oslo los análisis de D. LIU, "The 2015 Oslo Declaration on Arctic High Seas Fisheries: The Starting Point Towards Futures Fisheries Management in the Central Arctic Ocean", Arctic Yearbook, 2017, pp. 1-28; S. RYDER, "The Declaration Concerning the Prevention of Unregulated High Seas Fishing in the Central Arctic Ocean", The JCLOS Blog, 2015, pp. 1-8; así como E. J. MolenAAR, "The Oslo Declaration on High Seas ..., op. cit..

50 Vid., en este sentido, G. E. SHEPHARD et al., "Assessing the added value of the recent declaration on unregulated fishing for sustainable governance of the central Arctic Ocean", Marine Policy, 66 (2016), p. 53.
} 
instrumento no vinculante como es la Declaración de Oslo, un posible futuro instrumento jurídico vinculante recogiendo esta moratoria y una más lejana pero posible futura OROP, cuando las condiciones reales así lo exigiesen.

La Declaración de Oslo reconocía también los intereses reales de otros Estados en la pesca en la región y los alentaba a tomar medidas consistentes con las medidas provisionales adoptadas por los A5. Al mismo tiempo, los A5 esperaban "trabajar con ellos en un proceso más amplio para desarrollar medidas consistentes con esta Declaración que incluirían compromisos de todos los Estados interesados". Así fue como -sin que los A5 renunciaran por ello a su rol de liderazgo y especial responsabilidad- ese mismo año 2015 fueron invitados a una nueva reunión en Washington otras cinco grandes potencias con flotas pesqueras de altura no ribereñas del Océano Ártico central: Islandia, Corea del Sur, China ${ }^{51}$, Japón y la UE ${ }^{52}$. De esta manera, el proceso iniciado por los A5 se convertiría en el denominado "proceso ampliado" (Broader Process) o proceso "Five-plus-Five" (5+5), incorporando a estos otros sujetos de Derecho Internacional ${ }^{53}$. En todo caso, en esta reunión se siguió considerando -como se hizo en Oslo- que "es poco probable que haya una población o poblaciones de peces suficientes en la zona de alta mar del Océano Ártico central como para permitir una pesca comercial sostenible en esa zona en un futuro próximo"54.

Distintas reuniones celebradas entre los años 2016 y 2017 de este proceso ampliado 5+5 avanzaron en la determinación, a propuesta de los Estados Unidos, de la opción jurídica a seguir ${ }^{55}$ y confluyeron finalmente el 30 de

\footnotetext{
${ }^{51}$ A diferencia de los demás, China sigue sin ser parte en el Acuerdo sobre las poblaciones de peces de 1995.

52 Sobre la reunión de Washington vid. E.J. MolenAAR, "The December 2015 Washington Meeting on High Seas Fishing in the Central Arctic Ocean", The JCLOS Blog, 2016, pp. 1-10. La Unión Europea acogió favorablemente la Declaración de Oslo y, particularmente, la ampliación de las negociaciones para implicar a todos los actores pesqueros interesados [vid. Comunicación conjunta al Parlamento Europeo y al Consejo. Una política integrada de la Unión Europea para el Ártico, Documento JOIN(2016) 21 final, de 27 de abril de 2016, p.18, así como las Conclusiones del Consejo de Asuntos Exteriores sobre el Ártico, de 20 de junio de 2016, Documento 10400/16, apartado 9). En general sobre la política de la Unión Europea en relación con el Ártico vid. M. CAMPINS ERITJA, "The European Union and the North: Towards the Development of an EU Arctic Policy?", Ocean Yearbook, 27 (2013.1), pp. 459-485.

53 Asegurando así también la presencia de los otros Estados árticos: Islandia y la Unión Europea respecto de Suecia y Finlandia.

54 Vid. D. LIU, "The 2015 Oslo Declaration on Arctic High Seas Fisheries ...", op. cit., p. 13.

${ }^{55}$ Además de un proceso que podía ser por etapas, en las distintas reuniones (particularmente en la de Washington de diciembre de 2015, la primera del proceso 5+5, vid. Chairman's
} 
noviembre de 2017, cuando los cinco Estados ribereños árticos con los otros cinco participantes en el proceso adoptaron el Acuerdo POAC que fue firmado por las diez partes el 3 de octubre de 2018 y que en el apartado siguiente es objeto de análisis específico. Debe, sin embargo, subrayarse que el proceso llevado a cabo por los cincos Estados ribereños árticos ampliado a otros cinco sujetos internacionales, invitados por los primeros a incorporarse, ha sido un proceso que se ha caracterizado por su carácter no abierto lo que, como mínimo, es altamente discutible ${ }^{56}$ y no deja de tener consecuencias, como veremos, en la implementación futura del Acuerdo POAC ${ }^{57}$.

\section{ANÁLISIS DEL ACUERDO PARA IMPEDIR LA PESCA NO REGLAMENTADA EN ALTA MAR EN EL OCÉANO ÁRTICO CENTRAL}

El estudio específico del Acuerdo POAC $^{58}$ se aborda analizando, en primer lugar, sus objetivos y ámbito de aplicación (1), para continuar con el alcance de la regulación establecida para impedir la pesca no reglamentada (2). Estos aspectos centrales del Acuerdo son complementados con el análisis de las disposiciones sobre la investigación científica sobre los recursos marinos vivos (3), y de las disposiciones sobre las Partes y, en general, sobre la participación en el Acuerdo, así como en relación con sus perspectivas futuras (4).

\section{Los objetivos y el ámbito de aplicación del Acuerdo POAC.}

\footnotetext{
Statement, disponible en https://2009-2017.state.gov/e/oes/rls/pr/250352.htm) se plantearon tres opciones jurídicas posibles: profundizar en la Declaración de Oslo adoptando una declaración más amplia y no obligatoria; negociar un acuerdo internacional jurídicamente vinculante que incorporara las medidas recogidas en la Declaración de Oslo; o establecer una o más OROPs o AROPs (vid. R. RAYFUSE, "The role of law in the regulation of fishing activities in the Central Arctic Ocean", Marine Policy, 2019, https://doi.org/10.1016/j.marpol.2019.103562, p. 4).

56 Vid. en este sentido, M. SOBRIDO PRIETO, "La gestión de los recursos pesqueros ...", op. cit., p. 302.

${ }^{57}$ Lo que no fue obstáculo para que la Asamblea General de las Naciones Unidas acogiera con beneplácito la conclusión del Acuerdo POAC (vid. Resolución 73/125, de la Asamblea General, de 11 de diciembre de 2018, párr. 151).

58 Vid., también, otros recientes estudios sobre el Acuerdo POAC como los de V.J. SCHATZ, A. Proelss, N. LIU, "The 2018 Agreement to Prevent Unregulated High Seas Fisheries in the Central Arctic Ocean: A Critical Analysis", The International Journal of Marine and Coastal Law, 34 (2019), pp. 195-244; y R. RAYFUSE, "The role of law in the regulation of fishing activities ...", op. cit.
} 
Atendiendo a la situación potencial de que la pesca comercial en el Océano Ártico central deviniera posible, el objetivo fijado en el Acuerdo por sus partes firmantes es el de "prevenir la pesca no reglamentada en la zona de alta mar del Océano Ártico central a través de la aplicación de las medidas preventivas de conservación y ordenación como parte de una estrategia a largo plazo para salvaguardar unos ecosistemas marinos sanos, y para garantizar la conservación y la utilización sostenible de las poblaciones de peces"59. El núcleo de este objetivo deriva de la disminución de la capa de hielo debido al cambio climático y de los riesgos a los que, en consecuencia, pueden estar expuestos los ecosistemas del Océano Ártico central. De ahí que, en el mismo preámbulo del Acuerdo, se indique expresamente que, en consonancia con el criterio de precaución, se pretende prevenir el inicio de la pesca no reglamentada -lo que hace del Acuerdo una apuesta absolutamente innovadora ${ }^{60}$ y se reconozca la necesidad de nuevas medidas de conservación y ordenación.

Este objetivo se ajusta a los principios y disposiciones contenidos en los instrumentos internacionales pertinentes, de los que se cita expresamente la CNUDM, el Acuerdo sobre poblaciones de peces de 1995 y el Código de Conducta para la Pesca Responsable ${ }^{61}$. Es más, los apartados 3 y 4 del artículo 14 del Acuerdo configuran una auténtica cláusula de salvaguardia respecto de la inserción del mismo en el Derecho Internacional plasmado en la CNUDM y en el Acuerdo sobre las poblaciones de peces de 1995, así como en cualquier otro mecanismo internacional relativo a la ordenación de la pesca ${ }^{62}$. En este orden de ideas, también se establece que se aplicarán, mutatis mutandi, las disposiciones relativas a la solución de controversias estipuladas en el Acuerdo sobre las poblaciones de peces de 1995 a cualquier controversia

\footnotetext{
${ }^{59}$ Artículo 2 del Acuerdo.

${ }^{60}$ Como indican V.J. SchatZ, A. ProelSS, N. LIU, "The 2018 Agreement to Prevent Unregulated High Seas Fisheries ..., op. cit., p. 197, el Acuerdo POAC, a diferencia de otros Acuerdos pesqueros, puede ser el primer acuerdo regional adoptado antes de la introducción de las actividades pesqueras en un área determinada y que, más que establecer medidas de conservación y ordenación, establece directamente una moratoria de la pesca.

61 Párrafo 6 del preámbulo del Acuerdo.

62 De tal manera que las Partes reconocen también que seguirán estando vinculadas por sus obligaciones con arreglo a estas disposiciones del Derecho Internacional incluso en el supuesto de que el Acuerdo POAC expire o se denuncie sin que haya otro acuerdo sobre la conservación y ordenación de la pesca en la región (artículo 13.1 del Acuerdo).
} 
entre las Partes respecto a la interpretación o la aplicación del Acuerdo POAC $^{63}$.

Reseñado el objetivo general del Acuerdo y el marco normativo internacional en el que se inserta, debe abordarse ahora el ámbito de aplicación espacial, el ámbito de aplicación material y el ámbito de aplicación temporal del Acuerdo.

En relación con su ámbito de aplicación espacial, el Acuerdo abarca una determinada "zona" de alta mar del Océano Ártico, pero no todo el espacio marino de alta mar del Océano Ártico. Como ya se ha indicado, hay dos zonas de alta mar, el Banana Hole en el Mar de Noruega y el Loophole en el Mar de Barents, que no entran en el ámbito de aplicación del Acuerdo. Tampoco todo el Océano Ártico central se encuentra dentro del ámbito de aplicación del Acuerdo, puesto que hay espacios que pertenecen a la jurisdicción de los Estados y el Acuerdo sólo se refiere al espacio marino de alta mar. El Acuerdo se limita, por tanto, a las aguas de alta mar del Océano Ártico central que son definidas en el artículo 1, letra a) del Acuerdo como la zona de alta mar del Océano Ártico central que está rodeada de aguas sobre las que los Estados ribereños "ejercen su jurisdicción en materia de pesca". En otras palabras, el Acuerdo abarca los 2,8 millones de quilómetros cuadrados a los que nos hemos referido supra.

Respecto de su ámbito de aplicación material, el Acuerdo, a los efectos de prevenir la pesca no reglamentada, se refiere a la limitación de la pesca comercial y, en parte, de la pesca exploratoria, lo que comporta definir, en primer lugar, que se entiende por "pesca" y, en segundo lugar, que se entiende por "pesca comercial" y por "pesca exploratoria", aunque también resulta necesario determinar qué clases de recursos ictiológicos son objeto del Acuerdo. El artículo 1 del Acuerdo define todos estos conceptos. Por "pesca" se entiende "la búsqueda, captura, recogida o recolección de peces o cualquier actividad que pueda dar lugar, previsible y razonablemente, a la atracción, localización, captura, extracción o recolección de peces"64. Clarificando el ámbito de aplicación material del Acuerdo, el artículo 1, letra b) establece que se entiende por "peces" aquellas "especies de peces, moluscos y crustáceos,

\footnotetext{
${ }^{63}$ Artículo 7 del Acuerdo.

${ }^{64}$ Artículo 1, letra c) del Acuerdo.
} 
salvo los que pertenezcan a las especias sedentarias definidas en el artículo 77 de la CNUDM". En efecto, al igual que la regulación de la CNUDM relativa a la zona económica exclusiva no se aplica a las especies sedentarias ${ }^{65}$, tampoco se aplica este Acuerdo a estas especies. Esto resulta relevante porque, como es sabido, a los organismos vivos pertenecientes a especies sedentarias entendiendo por tales "aquellos que en el período de explotación están inmóviles en el lecho del mar o en su subsuelo o sólo pueden moverse en constante contacto físico con el lecho o el subsuelo"- se les aplica el régimen jurídico de la plataforma continental ${ }^{66}$.

Por su parte, por "pesca comercial" el Acuerdo se limita a indicar que se entiende "la pesca con fines comerciales"; mientras que por "pesca exploratoria" se entiende en el Acuerdo "la pesca practicada a efectos de evaluación de la sostenibilidad y la viabilidad del futuro de la pesca comercial, contribuyendo a los datos científicos relativos a esta actividad" 67 . Con estas definiciones de pesca comercial y de pesca exploratoria deben entenderse excluidas de ámbito de aplicación del Acuerdo otras modalidades de pesca, como la que se lleva a cabo con fines de investigación científica -de la que se ocupa en especial el mismo Acuerdo-, así como la pesca de subsistencia por poblaciones indígenas árticas o la pesca recreativa ${ }^{68}$.

Por lo que se refiere a su ámbito de aplicación temporal, el Acuerdo prevé su entrada en vigor a los 30 días de la fecha de recepción por el depositario de los instrumentos de manifestación del consentimiento de las diez partes -los nueve Estados y la UE- firmantes del Acuerdo69. Las disposiciones finales del Acuerdo no dejan de ser un poco confusas en lo que se refiere a la autenticación y manifestación del consentimiento en obligarse por el tratado ya que establecen que permanecerá abierto a la firma por las Partes por un período de 12 meses

\footnotetext{
65 Artículo 68 CNUDM.

${ }^{66}$ Artículo 77.4 de la CNUDM.

${ }^{67}$ Artículo 1, letra d) y letra e) del Acuerdo respectivamente.

${ }^{68}$ Que, al escapar de su ámbito de aplicación podrían generar potenciales problemas, aunque resulta difícilmente concebible hoy por hoy su ejercicio en aguas de alta mar del Océano Ártico central.

69 Artículo 11 del Acuerdo. En el momento de cerrar este trabajo (noviembre de 2019) todavía no está en vigor, pero ya tiene seis ratificaciones (Estados Unidos, Canadá, la Unión Europea, Japón, Rusia y Corea del Sur) de las diez necesarias. El depositario del Acuerdo es el Gobierno de Canadá (artículo 15 del Acuerdo). Un problema adicional se planteará cuando sea efectiva la retirada del Reino Unido de la Unión Europea, ya que se trata de una potencia pesquera con interés real en la zona del Acuerdo.
} 
desde el momento de la firma ${ }^{70}$ y que en relación con todos los firmantes el Acuerdo permanecerá abierto para su ratificación, aceptación o aprobación en cualquier momento ${ }^{71}$ y estará abierto a la adhesión de las Partes que aún no hayan firmado el Acuerdo también en cualquier momento ${ }^{72}$. Tratándose de un Acuerdo inicialmente cerrado a las diez Partes, la técnica jurídica de derecho de los tratados resulta confusa atendiendo, sobre todo, a que no entrará en vigor hasta la recepción de todos los instrumentos de ratificación, aceptación o aprobación, o adhesión del mismo, de todos los Estados enunciados en el artículo 9.1 y de la UE ${ }^{73}$.

Una vez en vigor, con la unanimidad de las diez partes negociadoras, se prevé que el Acuerdo se mantenga en vigor por un período inicial de dieciséis años ${ }^{74}$. En cualquier caso, este período inicial se podrá renovar automáticamente por períodos sucesivos de cinco años, a menos que cualquiera de las Partes presente una objeción formal a una prórroga del Acuerdo -es decir, un veto a la prórroga-, ya fuera en la última reunión de las Partes que tenga lugar antes de la expiración del período inicial o de cualquier período posterior de prórroga, o ya fuere enviando al depositario esta objeción a más tardar seis meses antes de la expiración del plazo correspondiente ${ }^{75}$. Tal como establece el artículo 5.1, letra a), corresponderá a las reuniones de las Partes examinar toda cuestión relativa a la duración del mismo. Lo que es subrayable es que la duración del Acuerdo inicialmente prevista -con lo que significa de limitación de la pesca comercial durante estos iniciales dieciséis años- coincide plenamente con las estimaciones científicas respecto de cuándo podrá ser posible fácticamente una actividad pesquera regular con finalidades comerciales. Estimaciones de las que se hace eco el mismo preámbulo del Acuerdo cuando se afirma "que es poco probable" la viabilidad de la pesca comercial en el Océano Ártico central en un futuro próximo ${ }^{76}$.

\footnotetext{
${ }^{70}$ Artículo 9.1 del Acuerdo.

${ }^{71}$ Artículo 9.2 del Acuerdo.

72 Artículo 10.1 del Acuerdo.

${ }^{73}$ Lo que, a mi juicio, evidencia también ciertas reticencias en relación con su futura entrada en vigor.

${ }^{74}$ Artículo 13.1 del Acuerdo.

75 Artículo 13.2 del Acuerdo. El plazo de seis meses es también el establecido para la efectividad de cualquier decisión de retirada del Acuerdo (artículo 12 del Acuerdo).

76 Párrafo 8 del preámbulo del Acuerdo.
} 


\section{El alcance de la limitación temporal de la pesca comercial en el} Acuerdo POAC

El eje central del Acuerdo gira en torno a este objetivo de prevenir la pesca no reglamentada en la zona de aplicación del mismo como mínimo durante estos dieciséis años de vigencia inicial del Acuerdo. En este sentido, resulta pertinente referirse ahora al concepto de "pesca no reglamentada" que, como se ha señalado supra, fue definido en el PAI-INDNR adoptado por la FAO en 2001. Se trata de una definición con una cierta ambigüedad que, no obstante, se ha consolidado ampliamente en el escenario internacional y que ha sido retomada y asumida asimismo por la UE en sus reglamentaciones contra la pesca INDNR ${ }^{77}$.

Así, en el PAI-INDNR se entiende por pesca no reglamentada las actividades pesqueras realizadas "en la zona de aplicación de una organización regional de ordenación pesquera competente que son realizadas por embarcaciones sin nacionalidad, o por embarcaciones que enarbolan el pabellón de un Estado que no es parte de esa organización, o por una entidad pesquera, de una manera que no está en consonancia con las medidas de conservación y ordenación de dicha organización, o que las contraviene; o en zonas o en relación con poblaciones de peces respecto de las cuales no existen medidas aplicables de conservación u ordenación y en las que dichas actividades pesqueras se llevan a cabo de una manera que no está en consonancia con las responsabilidades relativas a la conservación de los recursos marinos vivos que incumben al Estado en virtud del derecho internacional"78. Sólo una parte de la alta mar comprendida dentro del Océano Ártico central es objeto de reglamentación por parte de la CPANE, por lo que el resto de este espacio marino debe considerarse una zona en la que no existen medidas aplicables de conservación u ordenación; es decir, que tiene pleno encaje con lo dispuesto en el segundo párrafo de la definición que acabo de reproducir.

\footnotetext{
77 Normativa configurada esencialmente por el Reglamento (CE) 1005/2008, del Consejo, de 19 de septiembre de 2008 ( $D O$ L 286, de 29 de octubre de 2008) y el Reglamento (CE) 1010/2009, de la Comisión, de 22 de octubre de 2009 (DO L 280, de 27 de octubre de 2009). 78 Párrafo 3.3 del PAI-INDNR.
} 
Tal como está definida la pesca no reglamentada puede afirmarse que nos hallamos ante un concepto de difícil aprehensión, especialmente en su segundo apartado -que es, además, el aplicable a la mayor parte de la zona del Océano Ártico central-, puesto que el hecho de que no exista la correspondiente reglamentación no comporta, necesariamente, que la actividad pesquera resulte dañina, deba perseguirse y deba asociarse a la pesca ilegal. De la definición del PAI-INDNR se desprende que deben confluir dos condiciones: de un lado, el hecho de que no exista reglamentación aplicable; y, de otro lado, la conjunción copulativa "y" añade como condición que las actividades pesqueras se lleven a cabo de una manera que no esté en consonancia con las responsabilidades de conservación de los recursos marinos que incumben al Estado de pabellón de conformidad con el Derecho Internacional. El párrafo 3.4 del PAI-INDNR se refiere, precisamente, a esta última consideración al establecer, como cláusula de salvaguardia, que "puede que cierta pesca no reglamentada tenga lugar de una manera que no esté en violación del derecho internacional aplicable, y que tal vez no requiera la aplicación de las medidas previstas en el Plan de Acción Internacional". Pero ni en el Plan ni en otros desarrollos internacionales sobre el fenómeno de la pesca INDNR se determina qué condiciones, qué consecuencias o a quién corresponden las pertinentes responsabilidades.

En este orden de ideas, la manera de concretar en el Acuerdo esta limitación de la pesca no reglamentada se hace a sensu contrario ya que, más que en términos de una prohibición, lo que se establece -tal como se hacía en la Declaración de Oslo- es que las Partes autorizarán a los buques de su pabellón a practicar la pesca comercial en la zona del Acuerdo únicamente si cumplen una de estas dos condiciones: por una parte, si se cumplen las medidas de conservación y ordenación para la gestión sostenible adoptadas por OROPs o AROPs que hayan sido o puedan ser establecidos para gestionar la pesca comercial con arreglo a normas internacionales reconocidas ${ }^{79}$; o, por otra parte, si se cumplen las medidas provisionales de conservación y ordenación que puedan haber establecido las Partes en el Acuerdo, si éstas determinasen que son necesarias en el momento en que decidiesen entablar negociaciones para

\footnotetext{
${ }^{79}$ Artículo 3.1, letra a) del Acuerdo
} 
establecer una 0 más OROPs $\circ \mathrm{AROPs}^{80}$. En otras palabras, solo podrá autorizarse la pesca comercial si ésta está "reglamentada", es decir, si está sujeta a condiciones precisas por lo que se refiere a las medidas aplicables de conservación y ordenación, hayan sido ya establecidas o lo puedan ser en el futuro.

De manera parecida, el artículo 3.3 del Acuerdo establece que las Partes podrán autorizar la pesca exploratoria a buques de su pabellón en la zona del Acuerdo únicamente si se cumplen las medidas de conservación y ordenación establecidas por las Partes sobre la base del artículo 5.1, letra d). Estas medidas de conservación y ordenación de la pesca exploratoria en la zona del Acuerdo deberán establecerse en un plazo de tres años a partir de la entrada en vigor del mismo y, por tanto, la pesca exploratoria no podrá autorizarse en términos temporales hasta que se hayan adoptado dichas medidas; es decir, hasta que ésta esté "reglamentada" por las Partes en el Acuerdo. En todo caso, la adopción de estas medidas no está supeditada a que se haya determinado proceder a entablar negociaciones para el establecimiento de un AROP u OROP, como sucede con la segunda de las condiciones para la autorización de la pesca comercial que he mencionado. Más concretamente, el mismo Acuerdo prevé que, entre otras cosas, dichas medidas deberán establecer que la pesca exploratoria no menoscabe el objetivo del Acuerdo; que se limitará la duración, alcance y magnitud de la pesca exploratoria a fin de reducir al mínimo las repercusiones en las poblaciones de peces; y que se sujetará esta pesca a los requisitos normalizados establecidos en el protocolo de intercambio de datos científicos que prevé el artículo 4.5 del Acuerdo ${ }^{81}$.

Además, el artículo 5 del Acuerdo establece en relación con la pesca exploratoria que una Parte sólo podrá autorizarla sobre la base de investigaciones científicas sólidas y si es coherente con el Programa conjunto de investigación; que la Parte que autorice la pesca exploratoria deberá notificar a las otras Partes sus planes para esta pesca, proporcionándoles

\footnotetext{
${ }^{80}$ Artículo 3.1, letra b) del Acuerdo con referencia directa a lo dispuesto en el artículo 5.1, letra c), inciso ii) del mismo Acuerdo.

${ }^{81}$ Artículo 5.1, letra d), incisos i) i ii) del Acuerdo.
} 
oportunidad de formular observaciones sobre estos planes $^{82}$; y que deberá realizar un seguimiento adecuado de la pesca exploratoria que haya autorizado e informará de los resultados de esta actividad a las demás Partes ${ }^{83}$.

De este enfoque pueden desprenderse diversas observaciones. En primer lugar, que la perspectiva general es que, en el futuro -en un plazo de tres años desde la entrada en vigor del Acuerdo- se podrán establecer medidas de conservación y ordenación que permitirán que una Parte autorice a sus buques la realización de pesca exploratoria, que deberá servir para evaluar la sostenibilidad y viabilidad ulterior de la pesca comercial. En cualquier caso, no nos hallaremos ante pesca no reglamentada porque, previamente, las Partes deberán haber establecido estas medidas de conservación y ordenación específicas para la pesca exploratoria. Puede parecer realista pensar que en un plazo de tres años desde la entrada en vigor del Acuerdo se puedan establecer medidas de conservación y ordenación para la pesca exploratoria, pero las condiciones y controles de esta pesca, las obligaciones de notificación a las demás Partes, los efectos de estas notificaciones y los seguimientos e informes de resultado se revelan poco sólidos y exigentes en términos de cumplimiento, por lo que habrá que estar a las reuniones de las Partes para examinar la futura aplicación del mismo.

En segundo lugar, que la posible autorización de la pesca comercial deberá supeditarse a las medidas de conservación y ordenación que ya hayan adoptado OROPs o AROPs y a las medidas provisionales que adopten las Partes cuando hayan decidido entablar negociaciones para establecer una OROP o AROP. Es decir, que la autorización de la pesca comercial queda más supeditada, en tiempo y en condiciones, que la autorización de la pesca exploratoria. Además, la pesca comercial resulta poco probable en un futuro próximo y, en todo caso, quizás, en el futuro, la pesca exploratoria pueda evidenciar su viabilidad. Para ese futuro momento, la pesca ya no será en ningún caso "no reglamentada" puesto que, o bien ya existirán medidas

82 Artículo 5.1, letra d), inciso iv). Debe notarse que la versión en español del Acuerdo publicada tanto en la propuesta de la Comisión [Documento $\operatorname{COM(2018)~} 454$ final, de 12 de junio de 2018, Anexo] como el texto finalmente publicado con ocasión de la celebración del Acuerdo (DOUE de 15 de marzo de 2019) singulariza y traduce erróneamente en esta disposición la referencia "after it has notified the other Parties of its plans" por "después de haber notificado a la otra Parte sus planes".

${ }^{83}$ Artículo 5.1, letra d), incisos iii), iv) y v) del Acuerdo. 
aplicables establecidas por AROPs u OROPs ya existentes o que se hayan establecido posteriormente o bien las Partes ya estarán dispuestas a negociar un futuro AROP o una OROP y, por tanto, habrán determinado otras medidas provisionales de conservación.

Lo cierto es, en tercer lugar, que todas estas remisiones del Acuerdo abren la puerta al futuro establecimiento de un AROP o de una OROP en la zona del Acuerdo lo que, como he indicado, hace algún tiempo que se plantea por las Partes. Sin embargo, esta perspectiva debe congraciarse, de un lado, con la referencia del preámbulo del Acuerdo en la que se reconoce que, en las circunstancias del momento de su celebración, resulta prematuro crear nuevas OROPs o nuevos AROPs, regionales o subregionales; $y$, de otro lado, que todo ello genera cierta confusión cuando podemos considerar, perfectamente, que el Acuerdo ya constituye, de por sí, un AROP84. En todo caso, de manera al mismo tiempo preventiva y coordinada, el artículo 13.3 del Acuerdo ya establece que las Partes procederán a efectuar una "transición efectiva" entre el presente Acuerdo y cualquier posible nuevo acuerdo que establezca nuevas OROPs o AROPs, regionales o subregionales, en la zona del Acuerdo.

De otro lado, el artículo 3.1, letra a) da plena cobertura a la actuación y a las medidas de conservación y ordenación que haya podido establecer la ya existente CPANE en su zona de operación y de la que sólo algunos Estados ribereños y la UE son partes. En este sentido, también en el preámbulo del Acuerdo se destaca la importancia de garantizar la cooperación y la coordinación entre las Partes y la CPANE y otros indeterminados mecanismos pertinentes para la gestión de la pesca que se establezcan y operen de acuerdo con el Derecho Internacional, así como con los organismos y programa internacionales pertinentes ${ }^{85}$. En este mismo sentido, el Acuerdo POAC no menoscaba ni entra en conflicto con el papel ni con el mandato de cualquier mecanismo internacional relativo a la ordenación de la pesca ${ }^{86}$.

\footnotetext{
${ }^{84}$ Como consideran también V.J. SChatZ, A. ProelSS, N. LIU, "The 2018 Agreement to Prevent Unregulated High Seas Fisheries ..", op. cit., pp. 239-240.

85 Párrafo 7 del preámbulo del Acuerdo.

${ }^{86} \mathrm{Ni}$ modificará los derechos ni las obligaciones de cualquier Parte que se deriven de otros acuerdos compatibles con el Acuerdo POAC y que no afecten al disfrute de los derechos ni al cumplimiento de las obligaciones que a las demás Partes correspondan en virtud de este Acuerdo (artículo 14.4 del Acuerdo).
} 
En todo caso, el artículo 5 del Acuerdo resulta central en relación con el seguimiento, revisión y posterior aplicación del Acuerdo, tanto que pone de manifiesto que, sobre la base de la información derivada del Programa conjunto de investigación científica y teniendo en cuenta consideraciones medioambientales, "incluido el criterio de precaución" y los posibles efectos adversos en los ecosistemas, las Partes podrán tener en cuenta en sus reuniones "si la distribución, la migración y la abundancia de peces en la zona del Acuerdo permitiría apoyar la pesca sostenible" y, sobre esta base, determinar, entre otras cosas, "si procede entablar negociaciones para establecer una o más organizaciones o acuerdos regionales o subregionales de ordenación de la pesca para gestionar la pesca en la zona del Acuerdo" 87. Es decir, si la pesca comercial resultase viable, para que ésta fuera plenamente reglamentada debería plantearse el establecimiento de un específico AROP u OROP.

En todo ello debe subrayarse también que el mecanismo de adopción de decisiones en las reuniones de las Partes sobre las cuestiones de fondo 0 sustanciales será el del "consenso", entendiendo por ello la falta de cualquier objeción formal manifestada por alguna de las Partes ${ }^{88}$. En otras palabras, cualquier Parte puede vetar cualquier decisión sustantiva de las reuniones de las Partes. En este sentido, no sólo la misma prórroga del Acuerdo sino que la adopción de medidas provisionales de conservación y ordenación y el mismo enfoque del inicio de negociaciones para la creación futura de una AROP u OROP reflejan el difícil encaje entre, de un lado, la voluntad de los A5 de reforzar su liderazgo y su poder de veto ${ }^{89} \mathrm{y}$, de otro lado, la voluntad de los otros cinco participantes de limitar el potencial efecto del ejercicio de una jurisdicción progresiva o rampante por parte de los Estados ribereños árticos.

\footnotetext{
${ }^{87}$ Artículo 5.1, letra c, inciso i) del Acuerdo.

88 Artículo 6 del Acuerdo. En este mismo artículo se establece que las decisiones sobre cuestiones de procedimiento se adoptarán por mayoría de las Partes, pero también que una cuestión se considerará sustancial o de fondo si cualquiera de las Partes considera que lo es, con lo que se cierra el círculo y se reconoce la capacidad de veto individual.

89 No en vano el párrafo 4 del preámbulo del Acuerdo reconoce las responsabilidades especiales y los intereses particulares de los Estados ribereños del Océano Ártico central y el párrafo 5 formula una referencia específica a la Declaración de Oslo de 2015 adoptada, como he señalado supra, sólo por los Estados ribereños.
} 


\section{La investigación científica en el Acuerdo POAC}

En la Declaración de Oslo se formuló una apuesta por la investigación científica conjunta, que también es retenida en el Acuerdo POAC. En este sentido, el artículo 4.1 del Acuerdo establece que las Partes "facilitarán la cooperación en actividades científicas con el fin de incrementar el conocimiento de los recursos marinos vivos del Océano Ártico central y los ecosistemas que los albergan". Se prevé, además, que el Acuerdo no debe interpretarse en el sentido de que limite los derechos de las Partes en materia de investigación científica marina enunciados en la $\mathrm{CNUDM}^{90}$ y que, en cualquier caso, las actividades de investigación científica que impliquen la captura de peces en la zona del Acuerdo no han de menoscabar la prevención de la pesca comercial y exploratoria no reglamentada ni la protección de ecosistemas marinos saludables ${ }^{91}$.

En otras palabras, se reconoce el derecho de cada una de las Partes a llevar a cabo actividades de investigación científica marina, pero se apuesta preferentemente por un programa conjunto de investigación científica y seguimiento elaborado, coordinado y aplicado bajo la dirección de las Partes ${ }^{92}$. Este programa conjunto se establecerá en un plazo de dos años desde la entrada en vigor del Acuerdo y estará destinado a entender mejor los ecosistemas de la zona del Acuerdo, a determinar si en la zona existen actualmente o podrían existir en el futuro poblaciones de peces que podrían explotarse de forma sostenible, así como las posibles incidencias de este tipo de pesca en los ecosistemas de la zona ${ }^{93}$.

El establecimiento del programa conjunto a los dos años de la entrada en vigor del Acuerdo se ajusta a la adopción, en ese mismo plazo, de un protocolo de intercambio de datos que permita a las Partes compartir los datos pertinentes, directamente o través de las organizaciones, los organismos y los programas científicos y técnicos oportunos, cuyos trabajos se deberán tener en cuenta, así

\footnotetext{
${ }^{90}$ Artículo 3.7 del Acuerdo.

${ }^{91}$ Artículo 3.4 del Acuerdo, en el que se alienta a las Partes a que se informen mutuamente sobre sus planes para la autorización de tales actividades de investigación científica.

${ }^{92}$ Artículo 4.3 del Acuerdo.

${ }^{93}$ Artículo 4.2 del Acuerdo.
} 
como los conocimientos autóctonos y locales ${ }^{94}$. También en este plazo de dos años a partir de la entrada en vigor del Acuerdo, las Partes adoptarán las modalidades y procedimientos para las reuniones científicas conjuntas que se celebrarán, como mínimo, cada dos años y al menos dos meses antes de las reuniones de las Partes a fin de presentar los resultados de la investigación, examinar los datos científicos más fiables y facilitar dictámenes científicos con vistas a las reuniones de las Partes ${ }^{95}$. Aunque, como veremos, el Acuerdo reglamenta y establece plazos para la puesta en marcha del programa conjunto de investigación no fija claramente cómo funcionará este programa científico que, a fin de cuentas, es de suponer que continuará con la labor conjunta que se está efectuando desde la Declaración de Oslo ${ }^{96}$.

Será sobre la base de la información científica disponible, tanto del programa conjunto y de cualquier otra fuente pertinente, incluyendo los conocimientos autóctonos y locales, que las Partes, en sus reuniones previstas inicialmente cada dos años, podrán revisarla y, en su caso, adoptar decisiones ${ }^{97}$. En efecto, todo ello les ha de permitir examinar la aplicación del Acuerdo, incluso su duración, y, sobre la base de toda esta información, tener en cuenta si la distribución, la migración y la abundancia de peces en la zona del Acuerdo permiten en algún momento apoyar la pesca sostenible. A partir de esta consideración, las Partes podrán determinar si procede entablar negociaciones para establecer una o más AROP u OROP, o si, una vez entabladas negociaciones para ello, se deben establecer otras medidas provisionales de conservación y ordenación sostenible de los recursos pesqueros que permitan que las Partes autoricen pesca comercial, que será, por tanto, una "pesca reglamentada" 98.

\section{La participación en el Acuerdo y las perspectivas futuras del Acuerdo POAC.}

\footnotetext{
${ }^{94}$ Artículos 4.4 y 4.5 del Acuerdo.

${ }^{95}$ Artículo 4.6 del Acuerdo

${ }^{96}$ Aunque una completa "panártica" coordinación científica no existe todavía [vid. T.I. VAN PELT et al., "The missing middle: Central Arctic Ocean gaps in fishery research and science coordination", Marine Policy, 85 (2017), p. 85].

${ }^{97}$ Artículo 5.1, letra b) del Acuerdo.

${ }^{98}$ Artículo 5.1, letra c) del Acuerdo.
} 
En relación con la participación en el Acuerdo la cuestión clave estriba, como ya he indicado antes, en el carácter "no abierto" tanto del proceso $5+5$ como del mismo Acuerdo POAC. Más concretamente, el artículo 10.2 del Acuerdo prevé que, tras su entrada en vigor, "las Partes podrán invitar a que se adhieran al mismo otros Estados que tengan un interés real en la adhesión"99. El artículo 8 del Acuerdo sobre poblaciones de peces de 1995 prevé el criterio del "interés real" para poder ejercer el derecho a la participación en un AROP o una OROP, pero la previsión del Acuerdo POAC es la de la "invitación" por parte de las Partes, al igual que fueron invitados los otras cinco potencias pesqueras internacionales que se han convertido en las otras cinco Partes en el Acuerdo. Se trata de una invitación que, en el marco del Acuerdo, necesitará el "consenso" de las Partes en el mismo y que podrá ser objeto de veto individual.

Obviamente, hubiera sido mucho más criticable la celebración de un acuerdo cerrado y sólo entre los cinco Estados árticos ribereños, pero igualmente entiendo que aquí se está discriminado a otros posibles Estados con "interés real" en las actividades pesqueras en el Océano Ártico central. El problema es que esta restricción en la participación resulta común en bastantes AROPs y OROPs y constituye, ciertamente, uno de los nudos gordianos del proceso internacional de establecimiento de instrumentos y mecanismos para la conservación y ordenación sostenible de los recursos pesqueros ${ }^{100}$. Adicionalmente, puede considerarse también que las amenazas al ecosistema ártico proceden de fuera de la región, por lo que todos los Estados deberían poder participar en la mitigación de las consecuencias del cambio climático en el Ártico. En cualquier caso, más allá de la posible invitación para la futura adhesión, el artículo 8 del Acuerdo prevé que las Partes, de un lado, "animarán a los Estados que no son Partes en el presente Acuerdo a que adopten medidas conformes con las disposiciones del mismo"; y, de otro lado, "tomarán, de conformidad con el Derecho Internacional, medidas para disuadir a los

\footnotetext{
99 Para los que el Acuerdo entrará en vigor a los 30 días del depósito del instrumento de adhesión (artículo 11.2 del Acuerdo).

100 Vid., de manera general al respecto, el análisis de M. HINOJO ROJAS, "El acceso de terceros Estados a las organizaciones internacionales de pesca: una cuestión a revisar", en J.M. SOBRINO HEREDIA, La toma de decisiones en el ámbito marino: su repercusión en la cooperación internacional y en la situación de las gentes del mar, ed. Bomarzo, Albacete 2016, pp. 167-188.
} 
buques que enarbolen el pabellón de Estados que no son Parte de que realicen actividades que menoscaben la aplicación eficaz del presente Acuerdo".

Esta debilidad intrínseca respecto de la participación en todo el proceso pero, sobre todo, la debilidad endógena que representa la necesaria falta de objeción de alguna de las Partes -revestida en forma de consenso- para adoptar cualquier decisión de fondo sobre su futura continuidad, o sobre la invitación a otros Estados, o sobre la adopción de medidas provisionales de conservación y ordenación sostenible, o sobre el inicio de negociaciones para constituir un AROP o una OROP, regional o subregional, limitan gravemente la potencialidad futura del Acuerdo POAC. La misma entrada en vigor del Acuerdo está sometida a la ratificación por todas las Partes y, obviamente, cuando entre en vigor solo será obligatorio para los Estados parte y la UE. Lo que significa, de otro lado, que aquellos terceros Estados que no sean partes ni en el Acuerdo sobre las poblaciones de peces de $1995 \mathrm{ni}$ en este Acuerdo POAC podrían potencialmente seguir gozando de la tradicional libertad de pesca en alta mar en la zona de aplicación del Acuerdo.

En todo caso, la perspectiva de que en dieciséis años haya suficiente conocimiento científico como para poder optar a la creación de un AROP o una OROP evidencia también el profundo carácter adaptativo del Acuerdo POAC, tanto en su forma como en su contenido ${ }^{101}$. Sí que se prevé, como se ha indicado, que si se acaban estableciendo nuevas OROPs o AROPs, regionales o subregionales, en la zona del Acuerdo, las Partes procederán a efectuar una "transición efectiva" entre el Acuerdo POAC y cualquier otro acuerdo que se hubiera adoptado ${ }^{102}$. Además, uno de los problemas que se pondrán de manifiesto cuando entre en vigor el Acuerdo POAC y, en su caso, se empiecen a adoptar medidas provisionales de conservación y ordenación será el de la garantía de su aplicación. Obviamente, esto conduce a plantear la necesidad de mecanismos coercitivos y de sanción que pueden tener diversas opciones, como los controles por parte del Estado rector del puerto, la denegación de entrada o el uso de puertos, el fortalecimiento de los deberes del Estado de pabellón, el registro de buques pesqueros, los sistemas de observación de

\footnotetext{
101 R. RAYFUSE, "The role of law in the regulation of fishing ...", op. cit., p. 5.

102 Artículo 13.3 del Acuerdo.
} 
buques, la vigilancia e inspecciones y la cooperación en la aplicación de sanciones ${ }^{103}$.

Finamente y en otro orden de ideas, debe indicarse también que tanto en el preámbulo como en diversas disposiciones del Acuerdo se formulan referencias a las comunidades árticas o los pueblos indígenas árticos ${ }^{104}$. A los conocimientos autóctonos y locales ya nos hemos referido cuando se ha analizado el programa conjunto de investigación. Debe señalarse ahora que el artículo 5.2 del Acuerdo prevé que, para fomentar su cumplimiento, "las Partes podrán establecer comités u organismos similares en los que los representantes de las comunidades árticas, incluidos los pueblos indígenas árticos, puedan participar". Pero ni en el proceso de negociación del Acuerdo ha habido representación de los pueblos indígenas, ni en las reuniones de las Partes se contempla esta presencia, más allá de su posible incorporación en las delegaciones nacionales de algunas de las Partes. Parece más bien que la referencia a los pueblos indígenas árticos se ha acabado por convertir en una cláusula de estilo necesaria en este tipo de acuerdos, pero su implementación, ya sea de manera general o, específicamente, en el marco del Consejo Ártico, deja todavía mucho que desear.

\section{CONSIDERACIONES FINALES}

A título de consideraciones finales de este análisis sobre el futuro de la pesca en el Ártico y, en especial, sobre el Acuerdo POAC, quisiera señalar diversos aspectos. En primer lugar, deben mencionarse los importantes riesgos medioambientales para la región y para todo el planeta que el cambio climático y el calentamiento global está generando con la consiguiente reducción de la extensión y del espesor de la capa de hielo en el Océano Ártico. Estos riesgos globales no se ven compensados, en ningún caso, por las posibilidades de navegación, de explotación de hidrocarburos y las actividades pesqueras que

\footnotetext{
103 Vid., en este sentido, un análisis específico de los posibles mecanismos de aplicación de las medidas internacionales de conservación y ordenación de los recursos pesqueros en el alta mar del Océano Ártico en E. PAPASTAVRIDIS, "Fisheries Enforcement on the High Seas of the Arctic Ocean: Gaps, Solutions and the Potential Contribution of the European Union and Its Member States", The International Journal of Marine and Coastal Law, 33 (2018), en especial pp. 340-359

${ }_{104}$ Párrafos 10 y 11 del preámbulo del Acuerdo.
} 
el deshielo ártico pueda propiciar. La amenaza del cambio climático es demasiado gigante para todo el planeta y los seres vivos que lo habitan y quizás ya es demasiado tarde para intentar reducir sus efectos y sólo quepa mitigarlos.

En segundo lugar, debe indicarse que, en relación con la actividad pesquera, el enfoque de los Estados ribereños árticos y de otros actores pesqueros internacionales es claramente el de la aplicación del criterio de precaución. Ante la escasa información científica sobre los cambios en el ecosistema ártico y en los recursos marinos vivos se opta -de manera preventiva- por limitar la pesca no reglamentada. Se trata, en este sentido, de un enfoque anticipativo, de carácter preventivo -antes incluso de que pueda ser posible o viable la pesca comercial en la zona de aplicación del Acuerdo- y así se recoge, de manera reiterada, en las declaraciones pertinentes y en el mismo Acuerdo POAC.

Un Acuerdo POAC, en tercer lugar, que, bajo esta perspectiva preventiva, sólo autoriza la pesca en la medida en que haya reglamentación internacional y medidas de conservación y ordenación sostenible. Dicho de otra manera, establece una moratoria para la pesca comercial no reglamentada de dieciséis años y sólo se permitirá la pesca comercial si ésta está reglamentada, ya sea por medidas provisionales adoptadas en las reuniones de las Partes, ya sea estableciendo uno o más AROPs u OROPs, regionales o subregionales, ya sea, finalmente, en aplicación de las medidas ya adoptadas por la única OROP con competencia regulatoria en una limitada área del Océano Ártico central, la CPANE. En este sentido, entiendo también que el Acuerdo POAC, aunque no establezca inicialmente medidas específicas de conservación y ordenación sostenible, puede considerarse perfectamente un AROP como otros existentes.

En cuarto lugar, deben señalarse dos problemas importantes en la futura aplicación del Acuerdo POAC. De un lado, el que se refiere a su limitada participación, pues sólo comprende los cinco Estados ribereños del Océano Ártico central y los otros cinco sujetos de Derecho Internacional invitados a participar por los primeros, entre ellos la UE. El criterio que debería ser determinante y que está previsto convencionalmente es el de la existencia de un interés real en las pesquerías y no los intereses especiales de algunos 
Estados, los ribereños y los invitados por ellos. De otro lado, y en parte asociado a ello, debe ponerse de relieve el problema de la futura compatibilidad entre las medidas internacionales de conservación y ordenación sostenible en las aguas de alta mar del Océano Ártico central y las medidas adoptadas a escala nacional en las aguas árticas que se hallan bajo la jurisdicción de los Estados ribereños, que podrían resultar ser menos estrictas o incompatibles con las primeras.

En todo caso, no hay duda de que los próximos años pondrán en tensión toda esta arquitectura jurídica e institucional y corresponderá a todos los Estados, y en especial a los Estados ribereños árticos, una acción decidida y cooperativa en la mitigación de las consecuencias del cambio climático y en la posible viabilidad de la pesca comercial en el Océano Ártico central sometiéndola a medidas internacionales de conservación y ordenación sostenible. El reto es mayúsculo y no está claro que haya, hoy por hoy, la suficiente voluntad política para afrontarlo.

\section{BIBLIOGRAFÍA}

Alcaide Fernández, J., Cinelli, C., "La 'cuestión ártica' y el Derecho Internacional", Revista Española de Derecho Internacional, 2009.2, pp. 381-409

BARNES, R., "International Regulation of Fisheries Management in Arctic Waters", German Yearbook of International Law, 54 (2011), pp. 193-230.

Campins ERITJA, M., "The European Union and the North: Towards the Development of an EU Arctic Policy?", Ocean Yearbook, 27 (2013.1), pp. 459485.

CineluI, C., El Ártico ante el derecho del mar contemporáneo, Tirant lo Blanc, Valencia 2012.

CINELLI, C., "La protección del medio ambiente ártico: desarrollos recientes", en M. Sobrido Prieto (ed.), Espacios polares y cambio climático: desafíos jurídico-internacionales, ed. Tirant lo Blanch, Valencia 2017, pp. 167-184. 
Conde Pérez, E., "Geopolítica del Ártico: el Derecho Internacional ante los retos del cambio climático en la región", Cursos de Derecho Internacional y de Relaciones Internacionales de Vitoria-Gasteiz, UPH/UPV, 2015, pp. 99-160.

Conde Pérez, E., "Delimitaciones marítimas y territoriales en el Ártico: desarrollo y tendencias", Revista Española de Derecho Internacional, 2016.1, pp. 235-239.

Edeson, W., "The International Plan of Action on Illegal, Unreported and Unregulated Fishing: The Legal Context of a Non-Legally Binding Instrument", International Journal of Marine and coastal Law, 2001.6, pp. 603-623.

EuROPEAN PaRliament, Directorate-general for Internal Policies, Policy Department, Structural and Cohesion Policies, Fisheries Management and the Arctic in the Context of Climate Change, 2015.

DaUGiRdAS, K., MORTENSON, J.D., "United states reaches agreement to limit arctic fishing", American Journal of International Law, Vol. 112, 2018.2, pp. 313315.

Fallada García-Valle, J.R., "La gobernanza en el Ártico: entre el realismo, la utopía y la distopía", Revista Catalana de Dret Ambiental, Vol. IX, Núm. 1 (2018), pp. 1-40.

HinOJO ROJAS, M., "El acceso de terceros Estados a las organizaciones internacionales de pesca: una cuestión a revisar", en J.M. SoBRINO HEREDIA, La toma de decisiones en el ámbito marino: su repercusión en la cooperación internacional y en la situación de las gentes del mar, ed. Bomarzo, Albacete 2016, pp. 167-188.

LIU, D., "The 2015 Oslo Declaration on Arctic High Seas Fisheries: The Starting Point Towards Futures Fisheries Management in the Central Arctic Ocean", Arctic Yearbook, 2017, pp. 1-28.

Manero Salvador, A., El Deshielo del Ártico: Retos para el Derecho Internacional. La delimitación de los espacios marinos y la protección y preservación del medio ambiente, Aranzadi/Thomson Reuters, Cizur Menor 2011 
Manero Salvador, A., "La protección ambiental del Ártico y la Agenda 2030", Actualidad Jurídica Ambiental, núm. 77, 2018, pp. 3-34.

MolenAAR, E.J, "Arctic Fisheries and International Law: Gaps and Options to Address Them", Carbon and Climate law Review, 2012.1, pp. 63-77.

MolenAAR, E.J., "Status and Reform of International Arctic Fisheries Law", en E. TEDSEN et al. (eds.), Arctic Marine Governance, Springer-Verlag Berlin Heidelberg 2014, pp. 103-125.

MolenAAR, E.J., "Arctic Fisheries Management", en E.J. MolenaAR et al (eds.), The Law of the Sea and the Polar Regions: Interactions between Global and Regional Regimes, Martinus Nijhoff Publishers, Leyden 2013, pp. 243-266

MolenaAR, E.J., "The Oslo Declaration on High Seas Fishing in the Central Arctic Ocean", Arctic Yearbook, 2015, pp. 1-5.

MolenaAR, E.J., "The December 2015 Washington Meeting on High Seas Fishing in the Central Arctic Ocean", The JCLOS Blog, 2016, pp. 1-10

PapastaVRIDIS, E., "Fisheries Enforcement on the High Seas of the Arctic Ocean: Gaps, Solutions and the Potential Contribution of the European Union and Its Member States", The International Journal of Marine and Coastal Law, 33 (2018), pp. 324-360.

Pareja Alcaraz, P., "El Ártico, como espacio de cooperación: evolución, contenido y límites", en J.M. SOBRINO HEREDIA (coord.), Mares y Océanos en un mundo en cambio. Tendencias jurídicas, actores y factores, ed. Tirant lo Blanch, Valencia 2007, pp. 883-906.

PONS RAFOLS, X., "El protagonismo de la Unión Europea en la lucha contra la pesca ilegal, no declarada y no reglamentada", en J. PUEYO LOSA, J. JORGE URBINA (coord.), La gobernanza marítima europea: retos planteados por la reforma de la Política Pesquera Común, Thomson Reuters Aranzadi, Pamplona 2016, pp. 177-202.

RAYFUSE, R., "The role of law in the regulation of fishing activities in the Central Arctic Ocean", Marine Policy, 2019, https://doi.org/10.1016/j.marpol.2019.103562, pp. 1-6. 
Rey Aneiros, A., Sobrino HerediA, J.A., "Plan de acción internacional para prevenir, desalentar y eliminar la pesca ilegal, no declarada y no reglamentada (Organización de las Naciones Unidas para la Agricultura y la Alimentación, Roma, 2001)", Revista Española de Derecho Internacional, 2002.1, pp. 481-487 RYDER, S., "The Declaration Concerning the Prevention of Unregulated High Seas Fishing in the Central Arctic Ocean", The JCLOS Blog, 2015, pp. 1-8.

Schatz, V.J., Proelss, A., LiU, N., "The 2018 Agreement to Prevent Unregulated High Seas Fisheries in the Central Arctic Ocean: A Critical Analysis", The International Journal of Marine and Coastal Law, 34 (2019), pp. 195-244.

SHEPHARD, G.E, et al., "Assessing the added value of the recent declaration on unregulated fishing for sustainable governances of the central Arctic Ocean", Marine Policy, 66 (2016), pp. 50-57.

Sobrido PriETO, M., "La gestión de los recursos pesqueros árticos en alta mar", en J.M. Sobrino HeREDIA, La toma de decisiones en el ámbito marino: su repercusión en la cooperación internacional y en la situación de las gentes del mar, ed. Bomarzo, Albacete 2016, pp. 279-304.

TREVES, T., "La pesca ilegal, no declarada y no reglamentada: Estado del pabellón, Estado costero y Estado del Puerto", en J. PUEYO LOSA; J. JORGE URBINA (coords.), La cooperación internacional en la ordenación de los mares y océanos, ed. lustel, Madrid 2009, pp. 135-158.

Van Pelt, T.I, et al., "The missing middle: Central Arctic Ocean gaps in fishery research and science coordination", Marine Policy, 85 (2017), pp. 79-86.

VÁZqueZ GómEZ, E., Las Organizaciones internacionales de ordenación pesquera, Junta de Andalucía, Sevilla 2002.

VÁZQUEZ GÓMEZ, E, "La protección de la diversidad biológica marina más allá de la jurisdicción nacional. Hacia un nuevo acuerdo de aplicación de la Convención de Naciones Unidas sobre el Derecho del mar", Revista Electrónica de Estudios Internacionales, núm. 37 (2019)].

WEGGE, N., "The emerging politics of the Arctic Ocean. Future management of the living marine resources", Marine Policy, 51 (2015), pp. 331-338. 
WeidemanN, L., International Governance of the Arctic Marine Environment. With particular Emphasis on High Seas Fisheries, Springer, Hamburg Studies on Maritime Affairs, Vol. 27, 2014 